\title{
Regular Physical Exercise as a Strategy to Improve Antioxidant and Anti-Inflammatory Status: Benefits in Type 2 Diabetes Mellitus
}

\author{
Edite Teixeira de Lemos, ${ }^{1,2}$ Jorge Oliveira, ${ }^{2,3}$ João Páscoa Pinheiro, ${ }^{4}$ and Flávio Reis ${ }^{1}$ \\ ${ }^{1}$ Laboratory of Pharmacology and Experimental Therapeutics, IBILI, Medicine Faculty, University of Coimbra, \\ 3000-354 Coimbra, Portugal \\ ${ }^{2}$ ESAV, Polytechnic Institute of Viseu, 3504-510 Viseu, Portugal \\ ${ }^{3}$ Centre for the Study of Education, Technologies and Health, Polytechnic Institute of Viseu, 3504-510 Viseu, Portugal \\ ${ }^{4}$ Rehabilitation Medicine and Sports Medicine, Medicine Faculty, Coimbra University, 3000-354 Coimbra, Portugal \\ Correspondence should be addressed to Flávio Reis, freis@fmed.uc.pt
}

Received 20 April 2012; Revised 28 June 2012; Accepted 11 July 2012

Academic Editor: Chad M. Kerksick

Copyright () 2012 Edite Teixeira de Lemos et al. This is an open access article distributed under the Creative Commons Attribution License, which permits unrestricted use, distribution, and reproduction in any medium, provided the original work is properly cited.

Over the last 30 years the combination of both a sedentary lifestyle and excessive food availability has led to a significant increase in the prevalence of obesity and aggravation of rates of metabolic syndrome and type 2 diabetes mellitus (T2DM). Several lines of scientific evidence have been demonstrating that a low level of physical activity and decreased daily energy expenditure leads to the accumulation of visceral fat and, consequently, the activation of the oxidative stress/inflammation cascade, which underlies the development of insulin resistant T2DM and evolution of micro, and macrovascular complications. This paper focuses on the pathophysiological pathways associated with the involvement of oxidative stress and inflammation in the development of T2DM and the impact of regular physical exercise (training) as a natural antioxidant and anti-inflammatory strategy to prevent evolution of T2DM and its serious complications.

\section{Introduction}

Oxidation is viewed in general as a chemical process whereby electrons are removed from molecules, generating highly reactive free radicals, which include reactive oxygen species (ROS), such as superoxide and hydroperoxyl, and reactive nitrogen species (RNS) [1]. Reactive species arise as natural byproducts of aerobic metabolism at rest and play a role in several signalling cascades of distinct physiological processes, including phagocytosis, vasorelaxation, and neutrophil function $[2,3]$. Excessive levels of ROS or reduction of the antioxidant defenses, such as superoxide dismutases (SODs), heme oxygenase-1 (HO-1), NAD(P)H quinone oxidoreductase-1 (NQO-1), catalase or thioredoxin, causes oxidative stress, as has been repeatedly described for a number of various diseases, including type 2 diabetes mellitus (T2DM) [4-12].
Recent work has indicated that chronic inflammation, together with oxidative stress, is an important pathophysiological factor in the development of T2DM, in particular through the effects of proinflammatory cytokines, such as Creactive protein (CRP), tumor necrosis factor alpha (TNF$\alpha$ ), interleukin (IL)- 6 and IL- $1 \beta$, among others $[8,13$, 14]. On the contrary, anti-inflammatory cytokines, such as adiponectin and IL-10, seem to be protective against those pathological conditions, namely, by inhibiting TNF- $\alpha$ action on adhesion of endothelial cell, reducing nuclear factor (NF)$\kappa \mathrm{B}$ activation, and delaying macrophage foam-cell development [15-17]. Inflammatory cytokines are potent stimulators for the production of reactive species by macrophages and monocytes, thus inducing oxidative stress [18]. Additionally, and simultaneously, an increase in oxidative stress derived-inflammation has been hypothesized to be a major 
mechanism in the pathogenesis and progression of T2DM [19].

Regular exercise (with or without caloric restriction) has been increasingly viewed as an effective therapeutic strategy for the management of T2DM [20]. Indeed, aerobic and regular exercise improves metabolic status and insulin sensitivity, reducing the risk of cardiovascular disease [21]. Data from the literature suggest that acute exercise increases oxidative stress, in contrast to chronic exercise, in which adaptation to the stimulus decreases oxidative stress. Therefore, it appears that acute exercise induces the generation of ROS whereas exercise training maintains redox homeostasis [2224]. Concurrently, while a single bout of acute exercise is accompanied by a proinflammatory response that in many aspects is similar to those induced by infection and sepsis $[25,26]$, regular exercise has anti-inflammatory effects $[27$, 28]. Therefore, the objectives should be defined for each case, in a way that does not impair or overstimulate an immune response. Although there are clear benefits of exercise practice in diabetic patients, a detailed comprehension of the molecular basis underlying these helpful effects remains incomplete.

Based on the current literature, as well as on our knowledge concerning the effects of exercise training in an obese animal model of T2DM, the Zucker Diabetic Fatty (ZDF) rats, this paper will briefly review, firstly, the key pathophysiological aspects of the disease, focusing on the involvement of oxidative stress and inflammation and then the use of regular physical exercise of moderate intensity (training) as a strategy to improve antioxidant and anti-inflammatory status in T2DM.

\section{Oxidative Stress and Inflammation in Type 2 Diabetes Mellitus}

2.1. Oxidative Stress and T2DM. Increasing evidences link free radicals and oxidative stress to the pathogenesis of T2DM and development of complications [12, 29-32]. Several studies, both in animal models of diabetes and in diabetic patients, have shown that elevated extra- and intracellular glucose concentrations result in oxidative stress and contribute to the development and progression of diabetes and related complications [33-37].

Major sources of oxidative stress during diabetes include glucose autooxidation, overproduction of ROS by mitochondria, nonenzymatic glycation, and the polyol pathway $[38,39]$. In the latter, aldose reductase converts glucose into sorbitol with NADPH as a coenzyme; in diabetic conditions, increased flux through the polyol pathway enhances oxidative stress due to increased consumption of NADPH by aldose reductase. Since NADPH is required for generation of endogenous antioxidant glutathione (GSH), reduced NADPH availability depletes GSH, leading to greater oxidative stress $[40,41]$ (Figure 1). Other mechanism through which diabetes can increase oxidative stress involves electron transport in mitochondria. It has been proposed that high intracellular glucose levels increase the transfer of electrons through the electron transport chain in mitochondria during oxidative respiration, generating ROS [40, 42]. Furthermore, changes caused by diabetes alter the redox balance and affect redox-sensitive proteins, such as protein kinase C-epsilon, which enhances mitochondrial ROS production. Additionally, advanced glycation end-products (AGEs) generated under conditions of hyperglycemia stimulate NADPH oxidase that, in turn, can induce production of ROS (Figure 1). In a surprising development, augmented Wnt signaling stimulates mitochondrial biogenesis that can lead to increased ROS levels in mitochondria and greater oxidative damage [43]. Increased mitochondrial ROS is harmful by several reasons, including the damages caused on mitochondrial components, such as DNA, membrane proteins and lipids; opening of the mitochondrial permeability transition pore (MPTP) [44], thus releasing proapoptotic proteins from the mitochondria, such as cytochrome $\mathrm{c}$, that stimulate cell death. ROS generated in the mitochondrial respiratory chain have been proposed as secondary messengers for activation of NF- $\kappa$ B by TNF- $\alpha$ and IL-1 [42] (Figure 1). Although most data demonstrate mitochondria ROS overproduction (first of all superoxide) in diabetes and diabetic complications, some studies suggested that there are other key sources responsible for ROS overproduction (oxidative stress) in diabetes, such as glucose-stimulated superoxide formation catalyzed by NADPH oxidase $[45,46]$, or insulin (that stimulate superoxide formation catalyzed by NADPH oxidase) or even superoxide production catalyzed by xanthine oxidase $[47,48]$. Other studies have referred the role of lipoxygenases as producers of reactive radicals during enzymatic reactions $[49,50]$. Lipoxygenase products, especially $12(\mathrm{~S})$-HETE and 15(S)-HETE, are involved in the pathogenesis of several diseases, including diabetes, where they have proatherogenic effects and mediate the actions of growth factors and proinflammatory cytokines $[49,50]$.

Nonmitochondrial sources of ROS also include cyclooxygenase (COX) enzymes, which catalyze the synthesis of various prostaglandins. Pro-inflammatory cytokines seem to induce COX2 expression through NADPH oxidase stimulation and ROS production. Elevated levels of glucose are able to induce endothelium-derived vasoconstrictor prostanoids [51], suggesting a role for COX2 in diabetic vasculopathies. Further evidence supporting a role for oxidative stress in the induction of COX expression is the fact that expression of COX enzymes is normalized by glycemic control [52], and also by inhibition of oxidative phosphorylation, protein kinase $\mathrm{C}, \mathrm{NF}-\kappa \mathrm{B}[42]$ or by mutation of the NF $\kappa \mathrm{B}$ binding elements at the COX2 promoter site [53].

Another source of ROS is the cytochrome P450 monooxygenases, a large category of enzymes involved in the metabolism and detoxification of endogenous and exogenous compounds [54]. Diabetes affects the different isoforms of the cytochrome P450 system and seems to be responsible for adverse hepatic events associated with T2DM [54]. For example, there is an increased expression of CYP2E1 in T2DM [55] and in ob/ob mice and male fatty Zucker rat [56]. Due to a low degree of coupling between enzyme turnover and substrate binding, CYP2E1 has an unusually high capacity of generating free radicals, which are thought to result in lipid peroxidation, thus contributing to liver disease, 


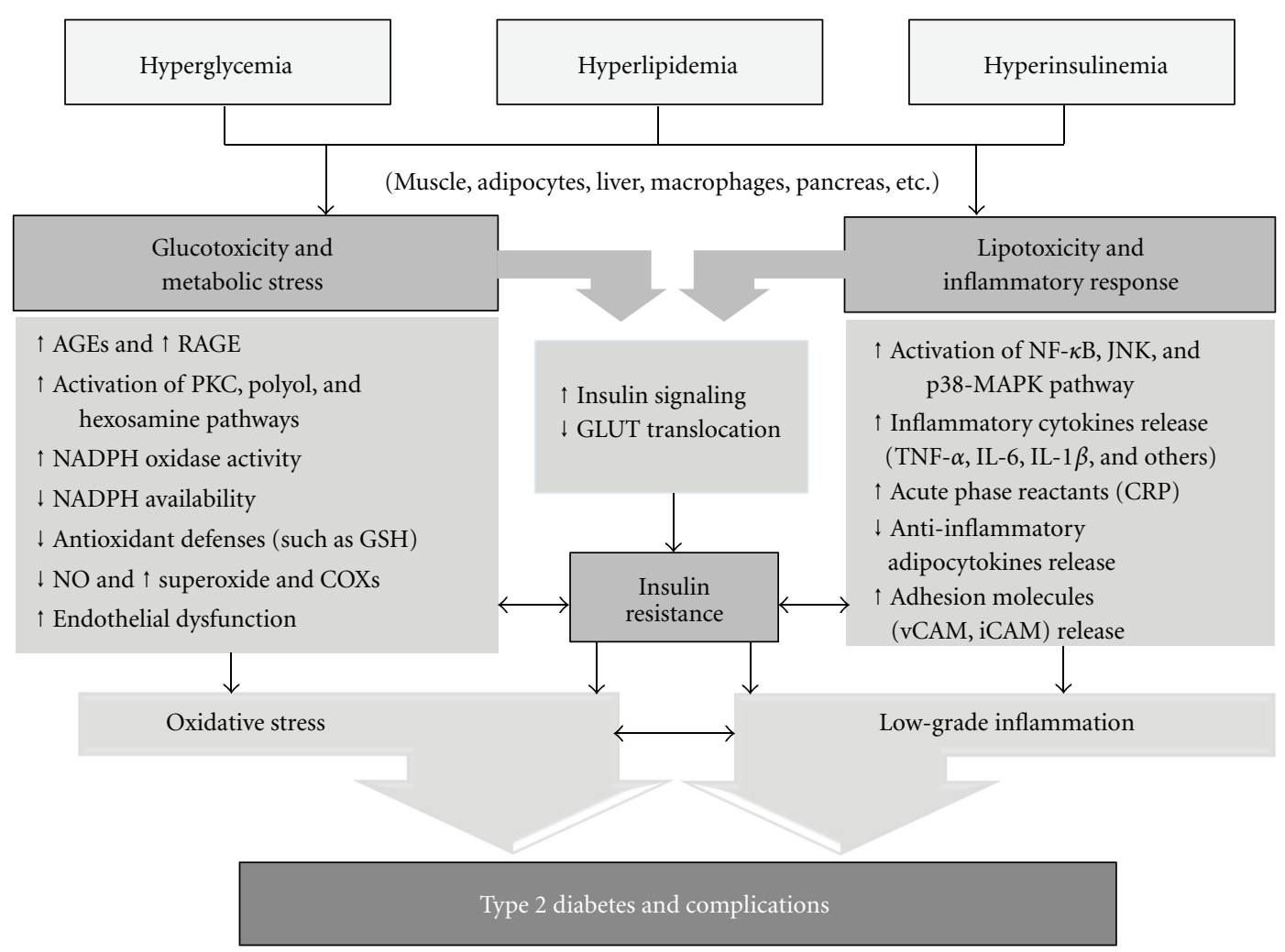

FIGURE 1: Schematic illustration of some of the key pathophysiological aspects involved in the development of T2DM, focusing on the involvement of oxidative stress and inflammation and underlying cellular/molecular mechanisms. AGEs, advanced glycation end-products; COXs, cyclooxygenases; CRP, C-reactive protein; GLUT, glucose transporter; GSH, endogenous antioxidant glutathione; iCAM, intracellular adhesion molecule-1; IL- $1 \beta$, interleukin $1 \beta$; IL-6, interleukin 6; JNK, Jun N-terminal kinase; p38-MAPK, mitogen-activated protein kinase; NADPH, nicotinamide adenine dinucleotide phosphate; NF-KB, factor nuclear kappa B; NO, nitric oxide; PKC, protein kinase C; RAGE, receptor of advanced glycation end-products; TNF- $\alpha$, tumor necrosis factor alpha; vCAM, vascular cell adhesion molecule.

including nonalcoholic steatohepatitis (NASH), which is closely associated with T2DM [57].

ROS activate a number of stress-sensitive kinases, whose downstream effects mediate insulin resistance. Therefore, activation of these kinases upregulates and activates nuclear factor kappa B (NF $\kappa$ B) and activator protein-1 (AP-1), which subsequently (i) activate c-Jun $\mathrm{N}$-terminal kinase (JNK) and inhibit NF $\kappa$ B kinase- $\beta$ (IKK), (ii) transcriptionally upregulate pro-inflammatory cytokine genes, and (iii) increase the synthesis of acute phase reactants (Figure 1).

2.2. Inflammation in T2DM. Obesity, as a result of inactivity and/or overeating, plays a key role in the development of insulin resistance and pancreatic beta-cell dysfunction. Increased triglycerides (TGs) stores, especially in visceral or deep subcutaneous adipose tissues, lead to large adipocytes which are resistant to insulin-evoked lipolysis suppression, then resulting in increased release of free fatty acids (FFAs) and glycerol. This "dyslipidaemic phenotype of diabetes," characterized by increased content of TGs and oxidized low density lipoproteins (ox-LDL), together with decreased levels of high density lipoproteins (HDL), is responsible for the lipotoxicity profile of diabetes (Figure 1). Lipotoxicity has been used to describe the deleterious effect of tissue fat accumulation on glucose metabolism and includes the notion that increased plasma FFA/intramyocellular levels of toxic lipid metabolites (such as long-chain fatty acyl CoAs, diacylglycerol and ceramides) play a role in the pathogenesis of muscle/liver insulin resistance [58].

Additionally, fat cells produce adipocytokines, interacting with several tissues such as muscle, liver, and arterial tissue where they exert deleterious effects on metabolism and vascular function. The adipose tissue of obese and T2DM individuals is infiltrated by mononuclear cells and is in a state of chronic inflammation [59]. The adipocytes and infiltrated macrophages secrete proinflammatory/prothrombotic cytokines, such as the TNF- $\alpha$, interleukin-6 (IL-6), resistin, adipsin, acylation-stimulating protein (ASP), plasminogen activator inhibitor 1 (PAI-1) and angiotensinogen, that promote atherogenesis and cause insulin resistance. Adipocytes also produce adiponectin, a potent insulin-sensitizing and antiatherogenic cytokine, now included in a vast group of substances named adipocytokines. Low adiponectin levels have been correlated with visceral obesity and whole-body insulin sensitivity [60]. This fat cell hormone acts as an 
insulin sensitizer, inhibiting TGs formation in liver and stimulating fatty acid oxidation in muscle through $5^{\prime}$ adenosine monophosphate-activated protein kinase (AMPK) and peroxisome proliferators activated receptor alpha (PPAR- $\alpha$ ) [61]. Despite their apparent importance in the insulin resistance syndrome, the aforementioned adipocytokines are just examples of a family of adipocyte-derived factors that modulate insulin resistance and systemic inflammation. Besides new adipocytokines, also certain myokines appear to affect insulin sensitivity and inflammatory responses. As such, the list of insulin (de)sensitizing proteins and cytokines is still far from complete. The secretion of cytokines depends not only on the amount of adipose tissue but also of its location visceral or intra-abdominal fat being more harmful than subcutaneous fat. The pro-inflammatory effects of cytokines occur via signaling cascades involving NF- $\kappa \mathrm{B}$ and JNKs pathways $[62,63]$. The increase of pro-inflammatory cytokines, associated with the dyslipidemic profile in T2DM, modulates the function and survival of pancreatic beta-cells. Several studies showed that exposure of beta-cells to high levels of saturated fatty acids and lipoproteins leads to their death. This effect is accelerated by hyperglycemia, demonstrating that lipotoxicity and glucotoxicity, in concert, determinate beta-cell failure [64-67] (Figure 1).

Inflammation has long been considered as a major risk factor in diabetes and associated with development and progression of diabetic complications [68]. Hyperglycemiainduced oxidative stress promotes inflammation through increased endothelial cell damage, microvascular permeability, and increased release of pro-inflammatory cytokines, including TNF- $\alpha$, IL-6, and IL- $1 \beta$, ultimately leading to decreased insulin sensitivity and evolution of diabetic complications $[69,70]$ (Figure 1).

2.3. The Oxidative-Inflammatory Cascade in T2DM. The above considerations direct us to consider a tight interaction between inflammation and oxidative stress that may be referred as the oxidative-inflammatory cascade (OIC) in T2DM. According to Lamb and Goldstein (2008), the OIC is a delicate balance modulated by mediators of the immune and metabolic systems and maintained through a positive feedback loop [1]. Within this cascade, ROS from the immune system, adipose tissue, and mitochondria mediate/activate stress-sensitive kinases, such as JNK, protein kinase $\mathrm{C}(\mathrm{PKC})$ isoforms, mitogen-activated protein kinase (p38-MAPK) and inhibitor of kappa B kinase (IKK-b). These kinases activate the expression of pro-inflammatory mediators, such as TNF- $\alpha$, IL-6, and monocyte chemoattractant protein-1 (MCP-1). The action of TNF- $\alpha$, MCP-1, and IL-6, locally and/or systemically, further induces the production of ROS, thus potentiating the positive feedback loop [71] (Figure 1).

The vascular dysfunction accompanies T2DM and it seems to be caused by the ROS-dependent adhesion molecules, such as intracellular adhesion molecule-1 (ICAM-1) and vascular cell adhesion molecule-1 (VCAM1 ), which facilitate the attraction, adhesion, and infiltration of white blood cells into sites of inflammation and the formation of vascular dysfunction $[72,73]$. The OIC-activated kinases are mainly responsible for the development of insulin resistance [74-76], beta cell dysfunction [77-79] and vascular dysfunction [80-82]. Therefore, modulation of OIC mechanisms involved in metabolic and immune processes can improve glucose metabolism, insulin resistance, vascular function and, consequently, delay the development of T2DM (Figure 1).

\section{Antioxidant and Anti-Inflammatory Effect of Exercise Training in T2DM}

A sedentary lifestyle is a risk factor for T2DM, with several clinical studies illustrating a reduction of mortality and morbidity in physically active individuals compared to sedentary individuals [83-85]. Exercise or physical activity may contribute to ameliorate insulin resistance by improving insulin action and vascular function (via increased nitric oxide (NO) bioavailability) as well as by increasing ROS-detoxification and decreasing ROS generation [86-89]. Even though the data obtained from animal studies cannot be directly extrapolated to humans, animal models of T2DM can offer excellent opportunities to evaluate experimental conditions and to assess tissues that cannot be tested in humans. Therefore, experimental studies have been contributing to improve the knowledge about the endocrine, metabolic, and morphological changes underlying the pathogenic mechanisms of the disease, as well as about the effectiveness of therapeutic options. In the following topics, we will review the benefits of regular aerobic exercise practice on antioxidant defenses and on inflammatory markers of T2DM, based on the information already available in the literature, from both clinical and experimental studies, as well as based on our experiments using the ZDF rat as a model of obese T2DM.

In order to avoid repeating the information throughout the text, the physical exercise program presented in our studies, which will be mentioned during the paper, was a regular and moderate intensity aerobic exercise (defined as training), consisting of 12 weeks ( $1 \mathrm{~h} /$ day, 3 times/week) of swimming program, voluntary, for both diabetic ZDF $\mathrm{fa} / \mathrm{fa}$ rats and lean $(\mathrm{ZDF}+/+)$ animals, between 8 and 20 weeks of age [90-92]. The animals were maintained under controlled temperature $\left(22^{\circ} \mathrm{C}\right)$, humidity $(60 \%)$, and lighting $(12 \mathrm{~h}$ of light) conditions, given a rodent maintenance chow (A04 Panlab, Barcelona, Spain) adjusted to their respective weights (100 mg/g of weight) and distilled water ad libitum. They perform their exercise in a cylindrical tank, $120 \mathrm{~cm}$ in diameter and $80 \mathrm{~cm}$ in height, containing water with a controlled temperature $\left(30-32^{\circ} \mathrm{C}\right)$; the animals were placed in the tank every day at the same hour (09.00-10.00 h) under the supervision of the same person; the swimming period was initially for $15 \mathrm{~min} / \mathrm{d}$ and was gradually increased such that the rats were able to perform exercise for $60 \mathrm{~min} / \mathrm{d}$, which was achieved in $1 \mathrm{wk}$; after $1 \mathrm{wk}$ of this training period, the rats were made to swim for $1 \mathrm{~h}$, three times a week; at the end of each exercise session, the animals were dried and kept in a warm environment; the sedentary rats were kept in the container where the swimming sessions were held for 
a period of $60 \mathrm{~min}$ to ensure that these control rats underwent the same amount of stress as the test animals that performed exercise. To minimize the acute effects of the exercise, exercised animals were sacrificed $48 \mathrm{~h}$ after the end of the last training session. The night before sacrifice, food was removed from the animals cages.

\subsection{Exercise Training as a Natural Antioxidant in T2DM}

3.1.1. Exercise and Oxidative Stress. In order to maintain homeostasis, cells have developed highly complex enzymatic and nonenzymatic antioxidant systems which, working synergistically, can protect the body against free radicalinduced damage. Enzymatic antioxidants include GLPx, CAT, SOD, HO-1, NAD $(\mathrm{P}) \mathrm{H}$ quinone oxidoreductase-1 (NQO-1), and thioredoxin [93]. Nonenzymatic antioxidants include vitamins $\mathrm{E}$ and $\mathrm{C}$, thiol antioxidants (glutathione, thioredoxin), among others [94]. In brief, SOD promotes the dismutation of the superoxide radical to form hydrogen peroxide $\left(\mathrm{H}_{2} \mathrm{O}_{2}\right)$ and oxygen; glutathione peroxidase ( $\left.\mathrm{GPx}\right)$ uses GSH as a reducing equivalent to reduce $\mathrm{H}_{2} \mathrm{O}_{2}$, thus generating oxidized glutathione and water; catalase converts $\mathrm{H}_{2} \mathrm{O}_{2}$ to water and oxygen; GSH can remove oxygen radicals directly and assist in the recycling of vitamins $\mathrm{C}$ and $\mathrm{E}$; peroxiredoxin III, which is a member of a newly identified family of peroxidases, is localizated within the mitochondria and seems to be a critical regulator of mitochondrial $\mathrm{H}_{2} \mathrm{O}_{2}$ concentrations, which promotes apoptosis in cooperation with other mediators of apoptotic signaling [95, 96]. All of these antioxidants are able to combine with ROS, generating less reactive species. Since production of ROS is a result of normal aerobic metabolism, under physiological conditions they are efficiently removed by cellular antioxidant systems.

Several studies have shown that chronic exercise training positively alters the oxidative homeostasis of cells and tissues by decreasing the basal levels of oxidative damage and increasing resistance to oxidative stress [97-101]. In fact, regular exercise causes adaptations in the antioxidant capacity, protecting cells against the harmful effects of oxidative stress, thus preventing cellular damage [102]. In healthy elderly men, after habitual physical activity, an enhancement of intrinsic antioxidant potential, and a reduction in lipid peroxidation occurs [103]. Adaptation to oxidative stress in trained individuals is clearly evidenced by a decrease in DNA damage, by sustained levels of protein oxidation and by an increment of resistance against chronic administration of hydrogen peroxide [103]. Training is also able to alter the metabolism of purines, reducing the availability of substrate for xanthine oxidase (XO) in the trained muscle and plasma content of hypoxanthine and uric acid [104]. Previous research has shown that exercise and physical activity upregulate antioxidant defences, which is the case of SODs in the cardiovascular systems $[105,106]$. Furthermore, the "nuclear factor erythroid 2-related factor 2 (Nrf2)" has recently been described as an important transcription factor against oxidative stress in health and during diabetes [107]. The ability of exercise to induce ROS activates Nrf2, which increase the expression of antioxidant enzymes, such as GPx, GST, and HO-1. However, there are no clear evidences concerning the putative influence of exercise training in Nrf2 signaling [108-110]. The importance of HO-1 in the antioxidant defense system occurs from an induction of ferritin synthesis, which diminishes the cellular pool of free iron and also from the enhancement of bilirubin levels, which are potent antioxidants $[111,112]$.

The above-reported protection happens under conditions of moderate exercise, while exhaustive exercise can clearly be damaging. During acute or extenuating conditions, exercise enhances the body's hemodynamic and metabolic responses [113]. An immediate effect of exercise is the increased maximal oxygen consumption $\left(\dot{\mathrm{VO}}_{2} \max \right)$ and metabolic activity, due to an increase in muscle contraction as a result of physical activity [114]. This condition leads to an imbalance between free radicals and antioxidants, as the increased consumption of oxygen for respiration generates increased amounts of ROS, mainly through leakage of electrons from the mitochondrial electron transport chain and the oxidation of xantine by xantine oxidase [115]. Despite the paradox that exhaustive exercise might induce ROS formation, mild oxidative stress produced by regular exercise appears to be able to reduce oxidative damage, as above described. The adaptive response, however, does not only depend on the degree of stress but also on preexisting conditions, as well as age, of the exercising subject.

3.1.2. Exercise and Oxidative Stress in T2DM. As commented above, in T2DM exercise decreases ROS generation, ameliorates insulin resistance, and improves vascular function [116]. Our group has demonstrated in diabetic ZDF animals submitted to a 12 -week swimming training protocol ( $3 \mathrm{~h} /$ week they will perform at a metabolic rate of 2-3 METs with a $\dot{\mathrm{VO}}_{2}$ ranging from 46 to $63 \mathrm{~mL} \cdot \mathrm{min}^{-1} \cdot \mathrm{kg}$ which means a moderate intensity exercise $\sim 45-65 \%$ of $\dot{\mathrm{VO}}_{2} \max$ ) an amelioration of insulin resistance and diabetic dysmetabolism. A decrease in systolic and mean blood pressure and in heart rate, alongside a diminishment of differential pressure, was also observed. The reduction of blood pressure suggests an improvement of vascular arterial compliance, with reduction in cardiac work and left ventricular hypertrophy amelioration $[92,117,118]$. The regular exercise was able to prevent serum oxidative stress, viewed by the reduction of lipid peroxidation, evaluated by malondialdehyde (MDA) levels, and by the increment of serum total antioxidant status (TAS) and SOD activity (Figures 2(a) and 2(b)), thus reinforcing the antioxidant action of training. Furthermore, the reduction of serum 3-nitrotyrosine (3-NT) levels in the trained diabetic rats suggests a decrease in peroxynitrite contents (Figure 2(c)). Our results were in agreement with others that have reported increased NO production in subjects who practiced chronic exercise, coincident with decrease in blood pressure and platelet activation [119]. Most of the clinical and experimental studies have reported beneficial effects of regular physical activity in increasing $\mathrm{NO}$ bioavailability and in reducing oxidative stress [120-122]. Physical activity increases eNOS expression and/or eNOS Ser phosphorylation [123], leading to a reduction of ROS generation, as well as to a beneficial influence on gene expression of antioxidant 

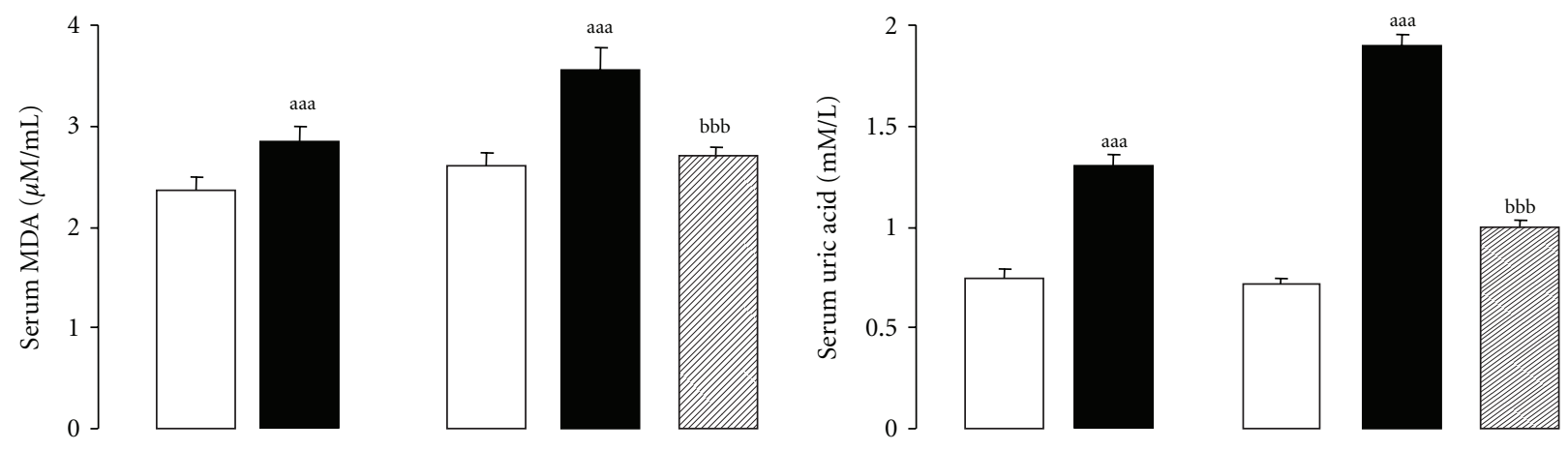

(a)
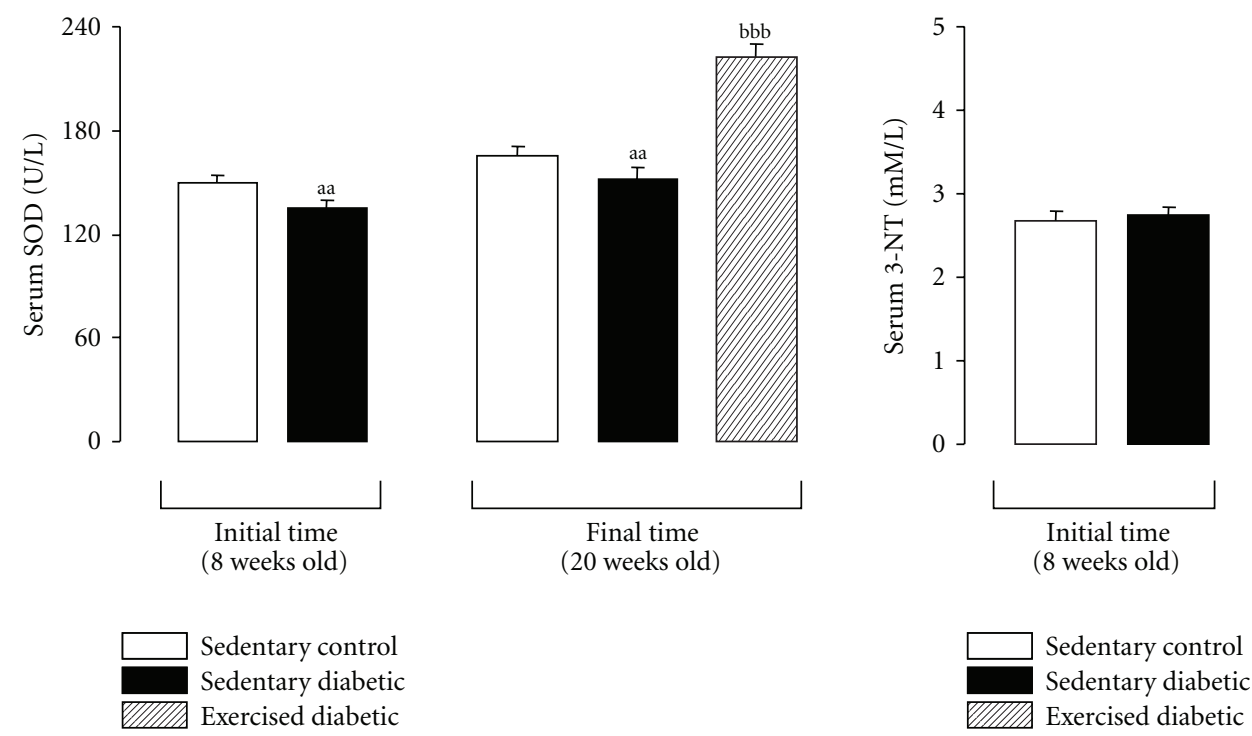

(c)

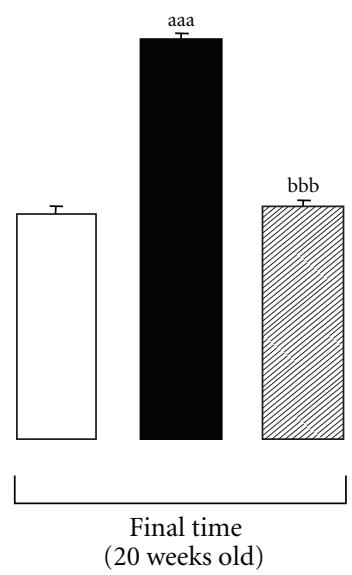

(b)

(d)

FIGURE 2: Evolution of serum MDA (a), SOD (b), uric acid (c), and 3-NT (d) levels between the initial time (8 weeks old) and the final time (20 weeks old) in sedentary control and diabetic rats and in diabetic exercised rats. Data are means \pm sem of eight values (rats) per group. Significant differences between sedentary diabetic and sedentary control rats: aa $P<0.01$ and aaa $P<0.001$. Significant differences between exercised diabetic and sedentary diabetic rats: ${ }^{\text {bb }} P<0.001$. MDA, malondialdehyde; SOD, superoxide dismutase; 3-NT, 3-nitrotyrosine.

enzymes, which promotes protective adaptations [124]. The upregulation of antioxidant defenses in animal models of T2DM was also observed by Nishida et al. [104], which also reported increased $\mathrm{Cu} / \mathrm{Zn}-\mathrm{SOD}$ protein production as a results of low-intensity exercise, in contrast with increased Mn-SOD after moderate intensity exercise [104]. Nevertheless, additional work is needed to assess the importance and physiological roles of this preferential upregulation in SODs by exercise in diabetes.

Although antioxidant properties have been attributed to uric acid, high levels of uric acid are strongly associated with the development of hypertension, visceral obesity, insulin resistance, dyslipidaemia, T2DM, kidney disease, and cardiovascular events $[125,126]$. Several studies suggest that, under certain concentrations, uric acid might have antioxidant activity, preventing lipid peroxidation; nevertheless, its association with chronic disease highlights the uric acid oxidant-antioxidant paradox [127]. Ideally, exercise training should be able to reduce pro-inflammatory levels of uric acid to antioxidant and protective levels. The results of de Lemos et al. [91] in ZDF rats submitted to 12 weeks of swimming training showed a decreased serum uric acid, to levels near those of the control rats (Figure 2(d)). Studies from other authors have reported that a six-month moderate intensity $\left(50-70 \% \mathrm{HR}_{\max }\right)$ aerobic exercise is able to decrease lipid peroxidation, as well as to increase GSH and catalase activity in T2DM and obese individuals $[128,129]$. A similar study in obese individuals reported attenuation in exerciseinduced lipid peroxidation following 24 weeks of a moderate intensity resistance training [130]. More recently, Oliveira et al. [131] compared the effects of 12 weeks training with 3 different types of exercise (aerobic training, strength training and combined training) on T2DM male and female human subjects, demonstrating that the aerobic training program provided important upregulation in antioxidant enzymes and increased NO bioavailability, which may help in minimizing oxidative stress and the development of the chronic complications of diabetes. 


\subsection{Exercise Training as a Natural Anti-Inflammatory in T2DM}

3.2.1. Exercise and Inflammation. The effects of regular or chronic exercise on basal levels of inflammatory markers have been used to recommend exercise as an antiinflammatory therapy. According to Kasapis and Thompson, a single session of exercise triggers an increase in proinflammatory cytokines release, associated with leukocytosis and increased plasma concentration of CRP [132]. This proinflammatory response to acute exercise is accompanied by a sudden increase in oxidative stress, followed by adaptive mechanisms against inflammation [133]. Moreover, a longitudinal study showed that regular training induces a reduction in CRP levels, suggesting an inflammatory action, visible in several conditions, including T2DM, insulin resistance, and other cardiovascular/cardiometabolic diseases. Regular exercise is associated with decreased contents of CRP, IL-6, and TNF- $\alpha$ and, simultaneously, increase of antiinflammatory substances, such as IL-4 and IL-10 [108], reinforcing the anti-inflammatory nature of exercise [134, 135].

Cytokines are released not only from mononuclear cells but also from muscle cells. Starkie et al. showed that physical exercise directly inhibits endotoxin-induced TNF- $\alpha$ production in humans, most likely through IL-6 release from exercising muscle [136]. Typically, IL-6 is the first cytokine present in circulation after exercise practice, followed by an increase in IL-1ra and IL-10 [137]. The ubiquitous role of IL-6 and the hypothesis of an exercise-induced antiinflammatory IL-6 release were recently reviewed $[138,139]$. Therefore, IL-6, a multifactorial cytokine, regulates cellular and humoral responses and plays a pivotal role in inflammation, being associated with several pathological conditions, including T2DM, and thus emerging as an independent early predictor for T2DM and as a marker of low-grade inflammation $[138,139]$. However, what is even more interesting concerning IL-6, as Fisman and Tenenbaum [138] commented, are the putative beneficial effects played as an anti-inflammatory factor, which is particularly evident in insulin sensitivity during exercise [138]. Therefore, a marked increase in circulating levels of IL-6 after exercise without muscle damage has been a remarkably consistent finding. The magnitude by which plasma IL-6 increases is related to exercise duration, intensity of effort, muscle mass involved in the mechanical work and endurance capacity [140]. IL-6 has been indicated as the strongest candidate for the humoral factor released after exercise, working in a hormone-like fashion, in which it is released by the muscle, now viewed as an endocrine organ, for influencing other organs [139]. Although this hypothesis requires further clarification, the role of IL-6 as both the "good" and the "bad," depending on the circumstances, as commented by Fisman and Tenenbaum [138], opens a new angle on the way interleukins act, and in particular concerning the effects of exercise in insulin resistance and diabetes. In this anti-inflammatory environment, IL- 6 inhibits TNF- $\alpha$ production, as previously reported in animals [141]. Furthermore, exercise also suppresses secretion of TNF- $\alpha$ by pathways independent of IL- 6 , as shown by the results obtained with knockout mice for IL- 6 submitted to exercise [142]. Consistent with the improvement in inflammatory status, exercise also interferes with circulating adiponectin levels in T2DM.

The anti-inflammatory nature of exercise training has been associated to a reduced cardiovascular disease, particularly due the training-evoked increased expression of antioxidant and anti-inflammatory mediators in the vascular wall, which could directly inhibit atherosclerosis development [143]. The available information concerning the effects of physical exercise on adiponectin levels is scarce and divergent [144]. Several studies showed that chronic exercise (programs of 6 weeks to 6 months) did not induce changes in adiponectin levels [145]. Kriketos et al. also reported, after 2-3 sessions of moderate exercise, a remarkable increase in adiponectin levels $(260 \%)$ that remained elevated for 10 weeks, without body weight modifications [146]. The systematic review performed by Simpson and Singh [144], considering literature searches in databases conducted from ten years and including 8 randomized controlled trials, concluded that exercise of varying prescription increase serum adiponectin in $38 \%$ of the trials, demonstrating small-tomoderate effect sizes [144]. Nevertheless, the same study showed inconsistent data in the literature for increasing adiponectin levels after short-term exposure to robust aerobic or resistance training of moderate-to-high intensities, reinforcing the need for more studies reporting reliable findings concerning a clear relationship between changes in adiponectin contents and exercise mode, intensity, and frequency [144]. However it has been shown that muscle Adipo R-1 is elevated in response to physical exercise [147], which elevates metabolic signal transduction of adiponectin, then improving oxidative metabolism. Therefore, the regulation of these adipocytokines, including adiponectin, is likely to contribute to the prevention of T2DM by chronic exercise.

3.2.2. Exercise and Inflammation in T2DM. The protective effect of exercise against chronic inflammation associated diseases may, to some extent, be ascribed to an antiinflammatory activity. Several studies show that markers of inflammation are reduced following longer term behavioral changes involving reduced energy intake and increased physical activity [134]. The data mentioned herein highlighted the idea that the beneficial effect of exercise seems to be related to its ability to decrease inflammatory cytokines levels and/or increase anti-inflammatory ones, which might be also true for pathological conditions, such as T2DM. The results of the studies conducted by de Lemos et al., above mentioned $[90,117,118]$, clearly demonstrated the anti-inflammatory capacity of swimming exercise training in diabetic ZDF rat. Actually, training was able to prevent the increase of pro-inflammatory cytokines and CRP observed in the diabetic rats. Those findings were in the line of those of Martin-Cordero et al., which found that obese Zucker rats, a model of metabolic syndrome, present an impairment of pro-inflammatory cytokines (TNF- $\alpha$, IL-6, IL-1beta and interferon gamma(IFN- $\gamma$ )) release by macrophages, an effect that was improved by habitual physical activity $[148,149]$. de Lemos et al. [91] also found an increment of serum 


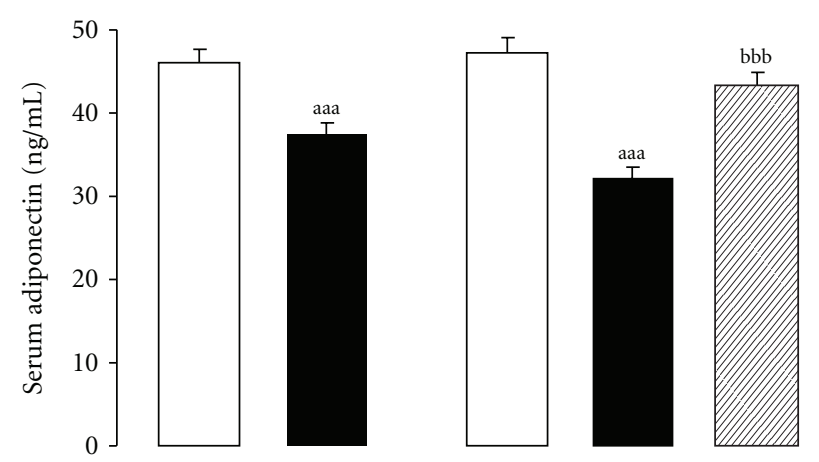

(a)

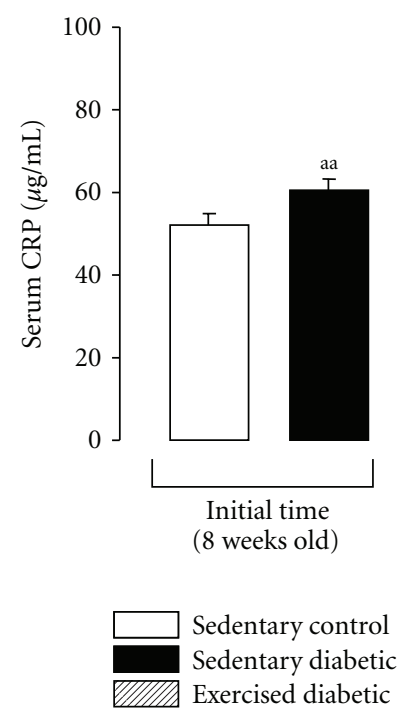

(20 weeks old)
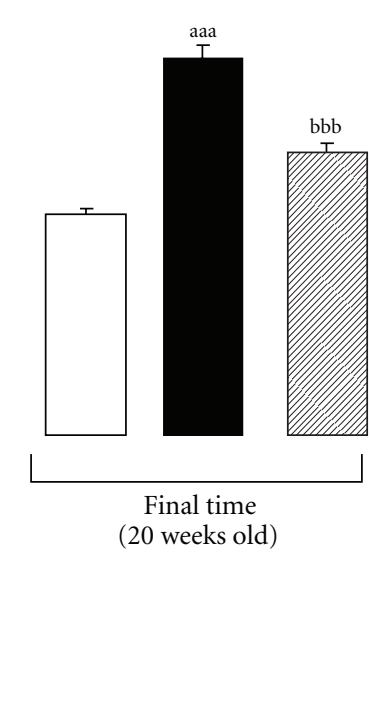

(b)
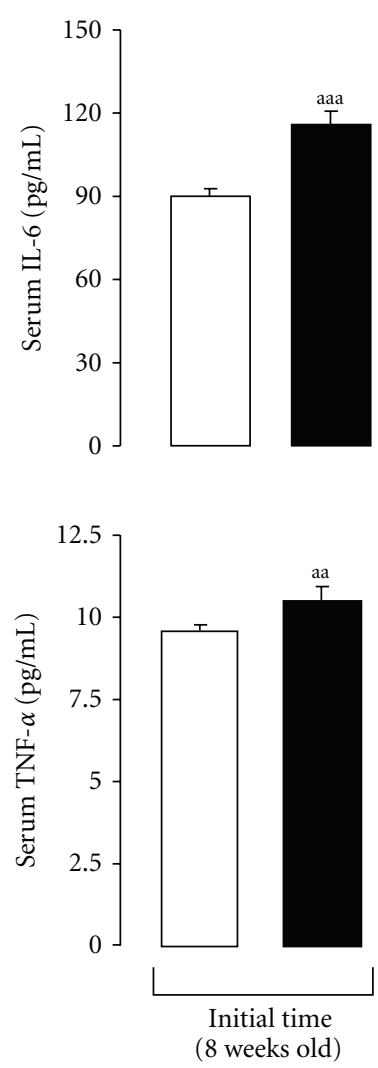

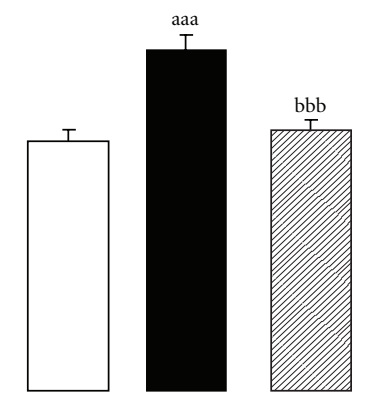

(c)

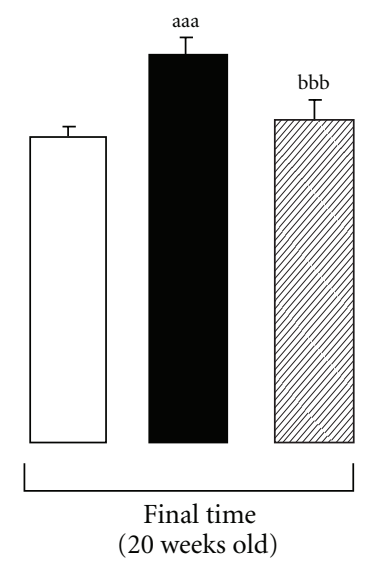

Sedentary control Sedentary diabetic Exercised diabetic

FIGURE 3: Evolution of serum adiponectin (a), CRP (b), IL-6 (c), and TNF- $\alpha$ (d) levels between the initial time (8 weeks old) and the final time (20 weeks old) in sedentary control and diabetic rats and in diabetic exercised rats. Data are means \pm sem of eight values (rats) per group. Significant differences between sedentary diabetic and sedentary control rats: ${ }^{\text {aa }} P<0.01$ and ${ }^{\text {aaa }} P<0.001$. Significant differences between exercised diabetic and sedentary diabetic rats: ${ }^{b b b} P<0.001$. CRP, C-reactive protein; IL-6, interleukin 6; TNF- $\alpha$, tumour necrosis factor alpha.

adiponectin in trained obese diabetic ZDF $(f a / f a)$ rats to levels near those found in the control lean rats (Figure 3(a)) [91]. Adiponectin anti-inflammatory actions have been associated with an improvement of cardiometabolic profile, which might be due, at least in part, to regulatory actions on other factors, including on CRP, IL-6, and TNF- $\alpha$ levels [150], which was also demonstrated in our study using the ZDF rat submitted to swimming exercise training (Figures $3(\mathrm{~b}), 3(\mathrm{c})$, and $3(\mathrm{~d})$ ). Considering that the adiponectin measurement was performed 48 hours after the last training session, the results may suggest an extension of the anti-inflammatory effect obtained by a single bout of exercise.

Pancreatic islets from type 2 diabetic patients present amyloid deposits, fibrosis, and increased cell death, which are associated with the inflammatory response [151]. T2DM is also characterized by hyperglycemia, dyslipidemia, increased circulating inflammatory factors and cellular stress, which are critical in precipitating islet inflammation in vivo. Chronic exposure of beta-cell to these mediators induces excessive production of ROS and activation of caspases, which inhibit insulin secretion and promote apoptosis of pancreatic betacells [152]. The impact of islet-derived inflammatory factors and islet inflammation on beta-cell function and mass may be either beneficial or deleterious. Therefore, depending on their roles in regulating pancreatic beta-cell function, some cytokines are protective while others can be detrimental. Actually, chronic exposure of islets to IL- $1 \beta$, IFN- $\gamma$, TNF- $\alpha$, and resistin inhibits insulin secretion and induces beta-cells apoptosis [153]. Other cytokines, such as adiponectin and visfatin, exert protective effects on pancreatic beta-cell function. In addition to circulating cytokines, islets also produce a variety of cytokines in response to physiologic and pathologic stimuli, and these locally-produced cytokines play important roles in regulation of pancreatic beta-cell function as well [153]. To maintain the normal pancreatic beta-cell function, the deleterious and protective cytokines need to be balanced. The abnormal control of cytokine profile in islets and in plasma is associated with pancreatic beta-cell 


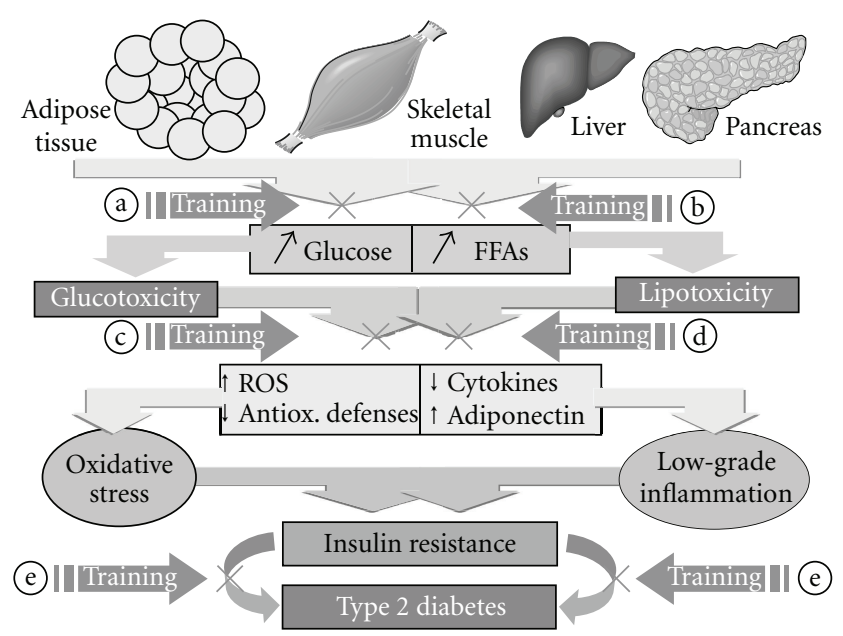

FIGURE 4: Schematic illustration of the proposed effects of regular physical exercise (training) in type 2 diabetes: exercise training exerts antihyperglycaemic (a), antidyslipidaemic (b), antioxidant (c), and anti-inflammatory (d) effects and thus prevents/delays the development of T2DM (E). FFAs, free fatty acids; ROS, reactive oxygen species.

dysfunction and T2DM [12]. All those emerging evidences reinforce the paradigm that islet inflammation is involved in the regulation of beta-cell function and survival in T2DM. Few studies have previously reported the putative beneficial effects of exercise training on pancreas, per se. Studies in Otsuka Long Evans Tokushima Fatty (OLETF), Goto-Kakizaki (GK), Zucker fatty (ZF), and ZDF rats have shown improvements in whole-body insulin sensitivity and preservation of beta-cell mass after exercise training [154, 155]. Insulin sensitivity improvements by exercise may confer an indirect beneficial effect on beta-cells by decreasing insulin demand and minimizing beta-cell exhaustion, at the same time ameliorating hyperglycemia-mediated loss in beta-cell function [156]; however, a direct effect on pancreatic function could not be excluded. Although almost every study has demonstrated beta-cell mass preservation with exercise training, none of them focused on inflammation. The recognition that islet inflammation is a key factor in TD2M pathogenesis has highlighted the concern regarding the protection of pancreatic islets and endocrine function. Therefore, restoring the normal cytokine profile in endocrine pancreas and plasma may hold great promise for more efficient beta-cell dysfunction treatment and T2DM management. de Lemos et al. [92] has demonstrated, using the ZDF rat as animal model of obese T2DM, that exercise training was able to prevent accumulation of pro-inflammatory cytokines (IL- 6 and TNF- $\alpha$ ) on endocrine pancreas. A decrease in pancreas immunostaining of both cytokines was observed, suggesting a protective effect of regular physical exercise against local inflammation.

\section{Conclusions and Perspectives}

Type 2 diabetes, cardiovascular diseases, colon cancer, breast cancer, and dementia constitute a cluster of diseases that defines "a diseasome of physical inactivity" [157], thus being of crucial importance to understand the mechanisms underlying the deleterious effects of physical inactivity and the beneficial actions of exercise training.

Oxidative stress, as well as inflammation, plays a critical role in the pathogenesis and progression of diabetes and diabetic-associated morbility. There are multiple sources of ROS production in diabetes, including those of mitochondrial and nonmitochondrial origins. Low-grade chronic inflammation is characterized by augmented systemic levels of some cytokines and CRP. The increased production of ROS and a concomitant decline of antioxidant defense mechanisms lead to the activation of adipose tissue and mitochondria mediate/activate stress-sensitive kinases. These kinases activate the expression of pro-inflammatory mediators that further induce the production of ROS and potentiate the positive feedback loop.

Emerging evidence suggests that exercise training activates the expression of cellular antioxidant systems, but is also able to produce ROS, which are by no means detrimental. Instead, they are required for normal force production in skeletal muscle, for the development of training-induced adaptation in endurance performance, as well as for the induction of endogenous defense systems [158-160]. Regular exercise is associated with lower levels of CRP, IL-6, and TNF$\alpha$ and, simultaneously, with increases in anti-inflammatory substances, such as adiponectin, IL-4 and IL-10. Therefore, regular and moderate exercise training can have antioxidant and anti-inflammatory systemic protective effects in type 2 diabetes (Figure 4). The health-beneficial effects of exerciseinduced myokines and heat shock protein are also gaining increased recognition.

Considering the data now reviewed, the evidences of beneficial effects of regular exercise may contribute to a growing awareness of potential risks by sedentary populations and public authorities and to a reinforcement of exercise prescription as adjuvant to drug therapy for treatment/attenuation of T2DM and its serious complications. However, further research is required to better understand the effects 
of exercise on inflammatory pathways and on the oxidative stress cascade. Furthermore, it will also be pivotal the proper establishment of type, duration, and intensity of training recommended in order to maximize the benefits of exercise training for the different subgroups of T2DM patients.

\section{Conflict of Interests}

The authors declare that they have no conflict of interests.

\section{References}

[1] R. E. Lamb and B. J. Goldstein, "Modulating an oxidativeinflammatory cascade: potential new treatment strategy for improving glucose metabolism, insulin resistance, and vascular function," International Journal of Clinical Practice, vol. 62, no. 7, pp. 1087-1095, 2008.

[2] S. Gupta, E. Chough, J. Daley et al., "Hyperglycemia increases endothelial superoxide that impairs smooth muscle cell $\mathrm{Na}^{+}$$\mathrm{K}^{+}$-ATpase activity," American Journal of Physiology, vol. 282, no. 3, pp. C560-C566, 2002.

[3] W. Dröge, "Free radicals in the physiological control of cell function," Physiological Reviews, vol. 82, no. 1, pp. 47-95, 2002.

[4] H. C. Lee and Y. H. Wei, "Oxidative stress, mitochondrial DNA mutation, and apoptosis in aging," Experimental Biology and Medicine, vol. 232, no. 5, pp. 592-606, 2007.

[5] P. Storz, "Reactive oxygen species in tumor progression," Frontiers in Bioscience, vol. 10, no. 2, pp. 1881-1896, 2005.

[6] N. R. Madamanchi, A. Vendrov, and M. S. Runge, "Oxidative stress and vascular disease," Arteriosclerosis, Thrombosis, and Vascular Biology, vol. 25, no. 1, pp. 29-38, 2005.

[7] C. Venkateshappa, G. Harish, R. B. Mythri et al., "Increased oxidative damage and decreased antioxidant function in aging human substantia nigra compared to striatum: implications for Parkinson's diseaseNeurochemical," Research, vol. 37, no. 2, pp. 358-369, 2012.

[8] J. C. Pickup, "Inflammation and activated innate immunity in the pathogenesis of type 2 diabletes," Diabetes Care, vol. 27, no. 3, pp. 813-823, 2004.

[9] P. Pacher, J. S. Beckman, and L. Liaudet, "Nitric oxide and peroxynitrite in health and disease," Physiological Reviews, vol. 87, no. 1, pp. 315-424, 2007.

[10] H. Yang, X. Jin, C. W. Kei Lam, and S. K. Yan, "Oxidative stress and diabetes mellitus," Clinical Chemical Laboratorial Medicine, vol. 49, no. 11, pp. 1773-1782, 2011.

[11] L. Gao and G. E. Mann, "Vascular NAD(P)H oxidase activation in diabetes: a double-edged sword in redox signalling," Cardiovascular Research, vol. 82, no. 1, pp. 9-20, 2009.

[12] A. Ceriello, K. Esposito, L. Piconi et al., "Oscillating glucose is more deleterious to endothelial function and oxidative stress than mean glucose in normal and type 2 diabetic patients," Diabetes, vol. 57, no. 5, pp. 1349-1354, 2008.

[13] P. C. Calder, R. Albers, J. M. Antoine et al., "Inflammatory disease processes and interactions with nutrition," British Journal of Nutrition, vol. 101, supplement 1, pp. S1-45, 2009.

[14] D. C. Lieb, K. Henri Parson, G. Mamikunian, and A. I. Vinik, "Cardiac autonomic imbalance in newly diagnosed and established diabetes is associated with markers of adipose tissue inflammation," Experimental Diabetes Research, vol. 2012, Article ID 878760, 8 pages, 2012.
[15] R. Jankord and B. Jemiolo, "Influence of physical activity on serum IL-6 and IL-10 levels in healthy older men," Medicine and Science in Sports and Exercise, vol. 36, no. 6, pp. 960-964, 2004.

[16] N. Ouchi, S. Kihara, Y. Arita et al., "Adiponectin, an adipocyte-derived plasma protein, inhibits endothelial NF- $\kappa$ B signaling through a cAMP-dependent pathway," Circulation, vol. 102, no. 11, pp. 1296-1301, 2000.

[17] C. S. Oliveira, F. M. A. Giuffrida, F. Crispim et al., "ADIPOQ and adiponectin: the common ground of hyperglycemia and coronary artery disease?" Arquivos Brasileiros de Endocrinologia \& Metabologia, vol. 55, no. 7, pp. 446-454, 2011.

[18] W. Huang and C. K. Glass, "Nuclear receptors and inflammation control: molecular mechanisms and pathophysiological relevance," Arteriosclerosis, Thrombosis, and Vascular Biology, vol. 30, no. 8, pp. 1542-1549, 2010.

[19] J. L. Evans, I. D. Goldfine, B. A. Maddux, and G. M. Grodsky, "Oxidative stress and stress-activated signaling pathways: a unifying hypothesis of type 2 diabetes," Endocrine Reviews, vol. 23, no. 5, pp. 599-622, 2002.

[20] J. Lindström, P. Ilanne-Parikka, M. Peltonen et al., "Sustained reduction in the incidence of type 2 diabetes by lifestyle intervention: follow-up of the Finnish Diabetes Prevention Study," The Lancet, vol. 368, no. 9548, pp. 1673-1679, 2006.

[21] S. S. Bassuk and J. E. Manson, "Epidemiological evidence for the role of physical activity in reducing risk of type 2 diabetes and cardiovascular disease," Journal of Applied Physiology, vol. 99, no. 3, pp. 1193-1204, 2005.

[22] J. Finaud, G. Lac, and E. Filaire, "Oxidative stress: relationship with exercise and training," Sports Medicine, vol. 36, no. 4, pp. 327-358, 2006.

[23] M. C. Gomez-Cabrera, E. Domenech, and J. Viña, "Moderate exercise is an antioxidant: upregulation of antioxidant genes by training," Free Radical Biology and Medicine, vol. 44, no. 2, pp. 126-131, 2008.

[24] G. Caimi, B. Canino, G. Amodeo, M. Montana, and R. L. Presti, "Lipid peroxidation and total antioxidant status in unprofessional athletes before and after a cardiopulmonary test," Clinical Hemorheology and Microcirculation, vol. 43, no. 3, pp. 235-241, 2009.

[25] M. Gleeson, "Immune function in sport and exercise," Journal of Applied Physiology, vol. 103, no. 2, pp. 693-699, 2007.

[26] B. K. Pedersen and L. Hoffman-Goetz, "Exercise and the immune system: regulation, integration, and adaptation," Physiological Reviews, vol. 80, no. 3, pp. 1055-1081, 2000.

[27] L. K. Stewart, M. G. Flynn, W. W. Campbell et al., "The influence of exercise training on inflammatory cytokines and C-reactive protein," Medicine and Science in Sports and Exercise, vol. 39, no. 10, pp. 1714-1719, 2007.

[28] K. L. Timmerman, M. G. Flynn, P. M. Coen, M. M. Markofski, and B. D. Pence, "Exercise training-induced lowering of inflammatory $\left(\mathrm{CD} 14^{+} \mathrm{CD} 16^{+}\right)$monocytes: a role in the anti-inflammatory influence of exercise?" Journal of Leukocyte Biology, vol. 84, no. 5, pp. 1271-1278, 2008.

[29] L. E. Fridlyand and L. H. Philipson, "Reactive species and early manifestation of insulin resistance in type 2 diabetes," Diabetes, Obesity and Metabolism, vol. 8, no. 2, pp. 136-145, 2006.

[30] A. Ceriello, "New insights on oxidative stress and diabetic complications may lead to a "causal" antioxidant therapy," Diabetes Care, vol. 26, no. 5, pp. 1589-1596, 2003.

[31] T. Heitzer, T. Schlinzig, K. Krohn, T. Meinertz, and T. Münzel, "Endothelial dysfunction, oxidative stress, and risk 
of cardiovascular events in patients with coronary artery disease," Circulation, vol. 104, no. 22, pp. 2673-2678, 2001.

[32] D. M. Niedowicz and D. L. Daleke, "The role of oxidative stress in diabetic complications," Cell Biochemistry and Biophysics, vol. 43, no. 2, pp. 289-330, 2005.

[33] A. Ceriello, L. Quagliaro, M. D’Amico et al., "Acute hyperglycemia induces nitrotyrosine formation and apoptosis in perfused heart from rat," Diabetes, vol. 51, no. 4, pp. 1076 1082, 2002.

[34] M. R. Sayed, M. M. Iman, and A. S. Dawlat, "Biochemical changes in experimental diabetes before and after treatment with mangifera indica and psidium guava extracts," Journal of Pharmaceutical and Biomedical Sciences, vol. 2, pp. 29-41, 2011.

[35] L. Zhang, A. Zalewski, Y. Liu et al., "Diabetes-induced oxidative stress and low-grade inflammation in porcine coronary arteries," Circulation, vol. 108, no. 4, pp. 472-478, 2003.

[36] L. Monnier, E. Mas, C. Ginet et al., "Activation of oxidative stress by acute glucose fluctuations compared with sustained chronic hyperglycemia in patients with type 2 diabetes," Journal of the American Medical Association, vol. 295, no. 14, pp. 1681-1687, 2006.

[37] D. Pitocco, F. Zaccardi, E. Di Stasio et al., "Role of asymmetric-dimethyl-l-arginine (ADMA) and nitrite/nitrate (NOx) in the pathogenesis of oxidative stress in female subjects with uncomplicated type 1 diabetes mellitus," Diabetes Research and Clinical Practice, vol. 86, no. 3, pp. 173-176, 2009.

[38] F. Giacco and M. Brownlee, "Oxidative stress and diabetic complications," Circulation Research, vol. 107, no. 9, pp. 1058-1070, 2010.

[39] J. L. Rains and S. K. Jain, "Oxidative stress, insulin signaling, and diabetes," Free Radical Biology and Medicine, vol. 50, no. 5, pp. 567-575, 2011.

[40] D. Pitocco, F. Zaccardi, E. Di Stasio et al., "Oxidative stress, nitric oxide, and diabetes," Review of Diabetic Studies, vol. 7, no. 1, pp. 15-25, 2010.

[41] I. Afanas'Ev, "Signaling of reactive oxygen and nitrogen species in diabetes mellitus," Oxidative Medicine and Cellular Longevity, vol. 3, no. 6, pp. 361-373, 2010.

[42] A. P. Rolo and C. M. Palmeira, "Diabetes and mitochondrial function: role of hyperglycemia and oxidative stress," Toxicology and Applied Pharmacology, vol. 212, no. 2, pp. 167-178, 2006.

[43] J. C. Yoon, A. Ng, B. H. Kim, A. Bianco, R. J. Xavier, and S. J. Elledge, "Wnt signaling regulates mitochondrial physiology and insulin sensitivity," Genes and Development, vol. 24, no. 14, pp. 1507-1518, 2010.

[44] C. Mantel, S. V. Messina-Graham, and H. E. Broxmeyer, "Superoxide flashes, reactive oxygen species, and the mitochondrial permeability transition pore: potential implications for hematopoietic stem cell function," Current Opinion in Hematology, vol. 18, no. 4, pp. 208-213, 2011.

[45] T. J. Guzik, S. Mussa, D. Gastaldi et al., "Mechanisms of increased vascular superoxide production in human diabetes mellitus: role of $\mathrm{NAD}(\mathrm{P}) \mathrm{H}$ oxidase and endothelial nitric oxide synthase," Circulation, vol. 105, no. 14, pp. 1656-1662, 2002.

[46] D. J. Leehey, M. A. Isreb, S. Marcic, A. K. Singh, and R. Singh, "Effect of high glucose on superoxide in human mesangial cells: role of angiotensin II," Nephron, vol. 100, no. 1, pp. 4653, 2005.
[47] M. Yang, E. Foster, and A. M. Kahn, "Insulin-stimulated $\mathrm{NAD}(\mathrm{P}) \mathrm{H}$ oxidase activity increases migration of cultured vascular smooth muscle cells," American Journal of Hypertension, vol. 18, no. 10, pp. 1329-1334, 2005.

[48] S. Matsumoto, I. Koshiishi, T. Inoguchi, H. Nawata, and H. Utsumi, "Confirmation of superoxide generation via xanthine oxidase in streptozotocin-induced diabetic mice," Free Radical Research, vol. 37, no. 7, pp. 767-772, 2003.

[49] R. Natarajan and J. L. Nadler, "Lipoxygenases and lipid signaling in vascular cells in diabetes," Frontiers in Bioscience, vol. 8, pp. s783-s795, 2003.

[50] P. Dandona and A. Aljada, "A rational approach to pathogenesis and treatment of type 2 diabetes mellitus, insulin resistance, inflammation, and atherosclerosis," American Journal of Cardiology, vol. 90, no. 5, pp. 27G-33G, 2002.

[51] N. Shanmugam, I. T. G. Gonzalo, and R. Natarajan, "Molecular mechanisms of high glucose-induced cyclooxygenase-2 expression in monocytes," Diabetes, vol. 53, no. 3, pp. 795802, 2004.

[52] S. Kiritoshi, T. Nishikawa, K. Sonoda et al., "Reactive oxygen species from mitochondria induce cyclooxygenase-2 gene expression in human mesangial cells: potential role in diabetic nephropathy," Diabetes, vol. 52, no. 10, pp. 2570-2577, 2003.

[53] A. A. Caro and A. I. Cederbaum, "Oxidative stress, toxicology, and pharmacology of CYP2E1," Annual Review of Pharmacology and Toxicology, vol. 44, pp. 27-42, 2004.

[54] R. A. DeFronzo, "Insulin resistance, lipotoxicity, type 2 diabetes and atherosclerosis: the missing links. The Claude Bernard Lecture 2009," Diabetologia, vol. 53, no. 7, pp. 12701287, 2010.

[55] Z. Wang, S. D. Hall, J. F. Maya, L. Li, A. Asghar, and J. C. Gorski, "Diabetes mellitus increases the in vivo activity of cytochrome P450 2E1 in humans," British Journal of Clinical Pharmacology, vol. 55, no. 1, pp. 77-85, 2003.

[56] A. Enriquez, I. Leclercq, G. C. Farrell, and G. Robertson, "Altered expression of hepatic CYP2E1 and CYP4A in obese, diabetic ob/ob mice, and fa/fa Zucker rats," Biochemical and Biophysical Research Communications, vol. 255, no. 2, pp. 300-306, 1999.

[57] H. Cortez-Pinto, M. C. De Moura, and C. P. Day, "Nonalcoholic steatohepatitis: from cell biology to clinical practice," Journal of Hepatology, vol. 44, no. 1, pp. 197-208, 2006.

[58] K. E. Wellen and G. S. Hotamisligil, "Obesity-induced inflammatory changes in adipose tissue," Journal of Clinical Investigation, vol. 112, no. 12, pp. 1785-1788, 2003.

[59] S. M. Furler, S. K. Gan, A. M. Poynten, D. J. Chisholm, L. V. Campbell, and A. D. Kriketos, "Relationship of adiponectin with insulin sensitivity in humans, independent of lipid availability," Obesity, vol. 14, no. 2, pp. 228-234, 2006.

[60] T. Kadowaki, T. Yamauchi, N. Kubota, K. Hara, K. Ueki, and $\mathrm{K}$. Tobe, "Adiponectin and adiponectin receptors in insulin resistance, diabetes, and the metabolic syndrome," Journal of Clinical Investigation, vol. 116, no. 7, pp. 1784-1792, 2006.

[61] W. Cai, L. Zhu, X. Chen, J. Uribarri, and M. Peppa, "Association of advanced glycoxidation end products and inflammation markers with thrombosis of arteriovenous grafts in hemodialysis patients," American Journal of Nephrology, vol. 26, no. 2, pp. 181-185, 2006.

[62] Y. Yano, E. C. Gabazza, N. Kitagawa et al., "Tumor necrosis, factor- $\alpha$ is associated with increased protein $\mathrm{C}$ activation in nonobese type 2 diabetic patients," Diabetes Care, vol. 27, no. 3, pp. 844-845, 2004. 
[63] K. Maedler, G. A. Spinas, D. Dyntar, W. Moritz, N. Kaiser, and M. Y. Donath, "Distinct effects of saturated and monounsaturated fatty acids on $\beta$-cell turnover and function," Diabetes, vol. 50, no. 1, pp. 69-76, 2001.

[64] M. Cnop, J. C. Hannaert, A. Y. Grupping, and D. G. Pipeleers, "Low density lipoprotein can cause death of islet $\beta$-cells by its cellular uptake and oxidative modification," Endocrinology, vol. 143, no. 9, pp. 3449-3453, 2002.

[65] W. El-Assaad, J. Buteau, M. L. Peyot et al., "Saturated fatty acids synergize with elevated glucose to cause pancreatic $\beta$ cell death," Endocrinology, vol. 144, no. 9, pp. 4154-4163, 2003.

[66] V. Poitout and R. P. Robertson, "Minireview: secondary $\beta$ cell failure in type 2 diabetes - a convergence of glucotoxicity and lipotoxicity," Endocrinology, vol. 143, no. 2, pp. 339-342, 2002.

[67] D. Tousoulis, A. M. Kampoli, N. Papageorgiou et al., "Pathophysiology of atherosclerosis: the role of inflammation," Current Pharmaceutical Design, vol. 17, no. 37, pp. 40894110, 2011.

[68] M. I. Schmidt, B. B. Duncan, A. R. Sharrett et al., "Markers of inflammation and prediction of diabetes mellitus in adults (Atherosclerosis Risk in Communities study): a cohort study," The Lancet, vol. 353, no. 9165, pp. 1649-1652, 1999.

[69] P. Dandona, A. Aljada, and A. Bandyopadhyay, "Inflammation: the link between insulin resistance, obesity and diabetes," Trends in Immunology, vol. 25, no. 1, pp. 4-7, 2004.

[70] A. Festa, R. D’Agostino, G. Howard, L. Mykkänen, R. P. Tracy, and S. M. Haffner, "Chronic subclinical inflammation as part of the insulin resistance syndrome: the insulin resistance atherosclerosis study (IRAS)," Circulation, vol. 102, no. 1, pp. 42-47, 2000.

[71] H. Kaneto, T. A. Matsuoka, N. Katakami et al., "Oxidative stress and the JNK pathway are involved in the development of type 1 and type 2 diabetes," Current Molecular Medicine, vol. 7, no. 7, pp. 674-686, 2007.

[72] Y. Taniyama and K. K. Griendling, "Reactive oxygen species in the vasculature: molecular and cellular mechanisms," Hypertension, vol. 42, no. 6, pp. 1075-1081, 2003.

[73] M. A. Creager, T. F. Lüscher, F. Cosentino, and J. A. Beckman, "Diabetes and vascular disease. Pathophysiology, clinical consequences, and medical therapy: part I," Circulation, vol. 108, no. 12, pp. 1527-1532, 2003.

[74] J. Hirosumi, G. Tuncman, L. Chang et al., "A central, role for JNK in obesity and insulin resistance," Nature, vol. 420, no. 6913, pp. 333-336, 2002.

[75] J. P. Bastard, M. Maachi, C. Lagathu et al., "Recent advances in the relationship between obesity, inflammation, and insulin resistance," European Cytokine Network, vol. 17, no. 1, pp. 4-12, 2006.

[76] J. F. Keaney Jr., M. G. Larson, R. S. Vasan et al., "Obesity and systemic oxidative stress: clinical correlates of oxidative stress in the Framingham Study," Arteriosclerosis, Thrombosis, and Vascular Biology, vol. 23, no. 3, pp. 434-439, 2003.

[77] V. Poitout and R. P. Robertson, "Glucolipotoxicity: fuel excess and $\beta$-cell dysfunction," Endocrine Reviews, vol. 29, no. 3, pp. 351-366, 2008.

[78] D. H. van Raalte and M. Diamant, "Glucolipotoxicity and beta cells in type 2 diabetes mellitus: target for durable therapy?" Diabetes Research and Clinical Practice, vol. 93,supplement 1, pp. S37-S46, 2011.

[79] J. D. McGarry, "Banting lecture 2001: dysregulation of fatty acid metabolism in the etiology of type 2 diabetes," Diabetes, vol. 51, no. 1, pp. 7-18, 2002.
[80] G. X. Shen, "Oxidative stress and diabetic cardiovascular disorders: roles of mitochondria and NADPH oxidase," Canadian Journal of Physiology and Pharmacology, vol. 88, no. 3, pp. 241-248, 2010.

[81] Z. Fatehi-Hassanabad, C. B. Chan, and B. L. Furman, "Reactive oxygen species and endothelial function in diabetes," European Journal of Pharmacology, vol. 636, no. 1-3, pp. 8$17,2010$.

[82] M. Goebeler, R. Gillitzer, K. Kilian et al., "Multiple signaling pathways regulate NF- $\kappa \mathrm{B}$-dependent transcription of the monocyte chemoattractant protein-1 gene in primary endothelial cells," Blood, vol. 97, no. 1, pp. 46-55, 2001.

[83] J. Lindström, A. Louheranta, M. Mannelin et al., "The finnish diabetes prevention study (DPS): lifestyle intervention and 3year results on diet and physical activity," Diabetes Care, vol. 26, no. 12, pp. 3230-3236, 2003.

[84] S. Kodama, S. Tanaka, K. Saito et al., "Effect of aerobic exercise training on serum levels of high-density lipoprotein cholesterol: a meta-analysis," Archives of Internal Medicine, vol. 167, no. 10, pp. 999-1008, 2007.

[85] T. Saito et al., "Lifestyle modification and prevention of type 2 diabetes in overweight Japanese with impaired fasting glucose levels: a randomized controlled trial," Archives of Internal Medicine, vol. 171, no. 15, pp. 1352-1360, 2011.

[86] N. Ahmadi, S. Eshaghian, R. Huizenga, K. Sosnin, R. Ebrahimi, and R. Siegel, "Effects of intense exercise and moderate caloric restriction on cardiovascular risk factors and inflammation," American Journal of Medicine, vol. 124, no. 10, pp. 978-982, 2011.

[87] C. A. Slentz, C. J. Tanner, L. A. Bateman et al., "Effects of exercise training intensity on pancreatic $\beta$-cell function," Diabetes Care, vol. 32, no. 10, pp. 1807-1811, 2009.

[88] M. F. Belotto, J. Magdalon, H. G. Rodrigues et al., "Moderate exercise improves leucocyte function and decreases inflammation in diabetes," Clinical and Experimental Immunology, vol. 162, no. 2, pp. 237-243, 2010.

[89] L. Bjork, N. T. Jenkins, S. Witkowski, and J. M. Hagberg, "Nitro-oxidative stress biomarkers in active and inactive men," International Journal of Sports Medicine, vol. 33, no. 4, pp. 279-284, 2012.

[90] E. T. de Lemos, F. Reis, S. Baptista et al., "Efeitos do exercício físico aeróbio no perfil metabólico e oxidativo de ratos diabéticos tipo 2," Boletim da SPHM, vol. 22, no. 1, pp. 16-28, 2007.

[91] E. T. de Lemos, F. Reis, S. Baptista et al., "Exercise training is associated with improved levels of C-reactive protein and adiponectin in ZDF (type 2) diabetic rats," Medical Science Monitor, vol. 13, no. 8, pp. BR168-BR174, 2007.

[92] E. Teixeira de Lemos, F. Reis, S. Baptista et al., "Exercise training decreases proinflammatory profile in Zucker diabetic (type 2) fatty rats," Nutrition, vol. 25, no. 3, pp. 330339, 2009.

[93] S. Lee, Y. Park, M. Y. Zuidema, M. Hannink, and C. Zhang, "Effects of interventions on oxidative stress and inflammation of cardiovascular diseases," World Journal of Cardiology, vol. 3, no. 1, pp. 18-24, 2011.

[94] S. Golbidi and I. Laher, "Antioxidant therapy in human endocrine disorders," Medical Science Monitor, vol. 16, no. 1, pp. RA9-RA24, 2010.

[95] T. S. Chang, C. S. Cho, S. Park, S. Yu, W. K. Sang, and G. R. Sue, "Peroxiredoxin III, a mitochondrion-specific peroxidase, regulates apoptotic signaling by mitochondria," Journal of Biological Chemistry, vol. 279, no. 40, pp. 41975-41984, 2004. 
[96] S. G. Rhee, S. W. Kang, T. S. Chang, W. Jeong, and K. Kim, "Peroxiredoxin, a novel family of peroxidases," IUBMB Life, vol. 52, no. 1-2, pp. 35-41, 2001.

[97] C. E. Cooper, N. B. Vollaard, T. Choueiri, and M. T. Wilson, "Exercise, free radicals and oxidative stress," Biochemical Society Transactions, vol. 30, no. 2, pp. 280-285, 2002.

[98] M. L. Urso and P. M. Clarkson, "Oxidative stress, exercise, and antioxidant supplementation," Toxicology, vol. 189, no. 1-2, pp. 41-54, 2003.

[99] C. K. Roberts, D. Won, S. Pruthi, S. S. Lin, and R. J. Barnard, "Effect of a diet and exercise intervention on oxidative stress, inflammation and monocyte adhesion in diabetic men," Diabetes Research and Clinical Practice, vol. 73, no. 3, pp. 249259, 2006.

[100] H. Nojima, H. Watanabe, K. Yamane et al., "Effect of aerobic exercise training on oxidative stress in patients with type 2 diabetes mellitus," Metabolism, vol. 57, no. 2, pp. 170-176, 2008.

[101] T. P. Wycherley, G. D. Brinkworth, M. Noakes, J. D. Buckley, and P. M. Clifton, "Effect of caloric restriction with and without exercise training on oxidative stress and endothelial function in obese subjects with type 2 diabetes," Diabetes, Obesity and Metabolism, vol. 10, no. 11, pp. 1062-1073, 2008.

[102] S. Golbidi, M. Badran, and I. Laher, "Antioxidant and anti-inflammatory effects of exercise in diabetic patients," Experimental Diabetes Research, vol. 2012, Article ID 941868, 16 pages, 2012.

[103] Z. Radák, M. Sasvári, C. Nyakas et al., "Regular training modulates the accumulation of reactive carbonyl derivatives in mitochondrial and cytosolic fractions of rat skeletal muscle," Archives of Biochemistry and Biophysics, vol. 383, no. 1, pp. 114-118, 2000.

[104] Y. Nishida, M. Iyadomi, Y. Higaki, H. Tanaka, M. Hara, and $\mathrm{K}$. Tanaka, "Influence of physical activity intensity and aerobic fitness on the anthropometric index and serum uric acid concentration in people with obesity," Internal Medicine, vol. 50, no. 19, pp. 2121-2128, 2011.

[105] F. Moien-Afshari, S. Ghosh, M. Khazaei, T. J. Kieffer, R. W. Brownsey, and I. Laher, "Exercise restores endothelial function independently of weight loss or hyperglycaemic status in db/db mice," Diabetologia, vol. 51, no. 7, pp. 13271337, 2008.

[106] J. Hollander, R. Fiebig, M. Gore et al., "Superoxide dismutase gene expression in skeletal muscle: fiber-specific adaptation to endurance training," American Journal of Physiology, vol. 277, no. 3, pp. R856-R862, 1999.

[107] Y. Zhi-Wen, L. Dan, L. Wen-Hua, and J. Tian-Ru, "Role of nuclear factor (erythroid-derived 2)-like 2 in metabolic homeostasis and insulin action: a novel opportunity for diabetes treatment?" World Journal of Diabetes, vol. 3, no. 1, pp. 19-28, 2012.

[108] J. S. Chen, P. H. Huang, C. H. Wang et al., "Nrf-2 mediated heme oxygenase-1 expression, an antioxidant-independent mechanism, contributes to anti-atherogenesis and vascular protective effects of Ginkgo biloba extract," Atherosclerosis, vol. 214, no. 2, pp. 301-309, 2011.

[109] M. D. Ferrer, A. Sureda, J. M. Batle, P. Tauler, J. A. Tur, and A. Pons, "Scuba diving enhances endogenous antioxidant defenses in lymphocytes and neutrophils," Free Radical Research, vol. 41, no. 3, pp. 274-281, 2007.

[110] A. M. Niess, F. Passek, I. Lorenz et al., "Expression of the antioxidant stress protein heme oxygenase-1 (HO-1) in human leukocytes: acute and adaptational responses to endurance exercise," Free Radical Biology and Medicine, vol. 26, no. 1-2, pp. 184-192, 1999.

[111] J. Peake and K. Suzuki, "Neutrophil activation, antioxidant supplements and exercise-induced oxidative stress," Exercise Immunology Review, vol. 10, pp. 129-141, 2004.

[112] T. Jansen, M. Hortmann, M. Oelze et al., "Conversion of biliverdin to bilirubin by biliverdin reductase contributes to endothelial cell protection by heme oxygenase-1-evidence for direct and indirect antioxidant actions of bilirubin," Journal of Molecular and Cellular Cardiology, vol. 49, no. 2, pp. 186195, 2010.

[113] P. D. Thompson, S. F. Crouse, B. Goodpaster, D. Kelley, N. Moyna, and L. Pescatello, "The acute versus the chronic response to exercise," Medicine and Science in Sports and Exercise, vol. 33, no. 6, supplement, pp. S438-S445, 2001.

[114] H. M. Alessio, A. E. Hagerman, B. K. Fulkerson, J. Ambrose, R. E. Rice, and R. L. Wiley, "Generation of reactive oxygen species after exhaustive aerobic and isometric exercise," Medicine and Science in Sports and Exercise, vol. 32, no. 9, pp. 1576-1581, 2000.

[115] J. Viña, A. Gimeno, J. Sastre et al., "Mechanism of free radical production in exhaustive exercise in humans and rats; role of xanthine oxidase and protection by allopurinol," IUBMB Life, vol. 49, no. 6, pp. 539-544, 2000.

[116] R. T. Iborra, I. C. D. Ribeiro, M. Q. T. S. Neves et al., "Aerobic exercise training improves the role of high-density lipoprotein antioxidant and reduces plasma lipid peroxidation in type 2 diabetes mellitus," Scandinavian Journal of Medicine and Science in Sports, vol. 18, no. 6, pp. 742-750, 2008.

[117] E. Teixeira de Lemos, R. Pinto, J. Oliveira et al., "Differential effects of acute (extenuating) and chronic (training) exercise on inflammation and oxidative stress status in an animal model of type 2 diabetes mellitus," Mediators of Inflammation, vol. 2011, Article ID 253061, 8 pages, 2011.

[118] E. Teixeira-Lemos, S. Nunes, F. Teixeira, and F. Reis, "Regular physical exercise training assists in preventing type 2 diabetes development: focus on its antioxidant and antiinflammatory properties," Cardiovascular Diabetology, vol. 10, article 12, 2011.

[119] T. Fukai, M. R. Siegfried, M. Ushio-Fukai, Y. Cheng, G. Kojda, and D. G. Harrison, "Regulation of the vascular extracellular superoxide dismutase by nitric oxide and exercise training," Journal of Clinical Investigation, vol. 105, no. 11, pp. 631-1639, 2000.

[120] N. Lauer, T. Suvorava, U. Rüther et al., "Critical involvement of hydrogen peroxide in exercise-induced up-regulation of endothelial NO synthase," Cardiovascular Research, vol. 65, no. 1, pp. 254-262, 2005.

[121] J. Grijalva, S. Hicks, X. Zhao et al., "Exercise training enhanced myocardial endothelial nitric oxide synthase (eNOS) function in diabetic Goto-Kakizaki (GK) rats," Cardiovascular Diabetology, vol. 7, article 34, 2008.

[122] T. P. Wycherley, G. D. Brinkworth, M. Noakes, J. D. Buckley, and P. M. Clifton, "Effect of caloric restriction with and without exercise training on oxidative stress and endothelial function in obese subjects with type 2 diabetes," Diabetes, Obesity and Metabolism, vol. 10, no. 11, pp. 1062-1073, 2008.

[123] R. Hambrecht, V. Adams, S. Erbs et al., "Regular physical activity improves endothelial function in patients with coronary artery disease by increasing phosphorylation of endothelial nitric oxide synthase," Circulation, vol. 107, no. 25, pp. 3152-3158, 2003. 
[124] C. Leeuwenburgh and J. W. Heinecke, "Oxidative stress and antioxidants in exercise," Current Medicinal Chemistry, vol. 8, no. 7, pp. 829-838, 2001.

[125] R. J. Johnson, D. H. Kang, D. Feig et al., "Is there a pathogenetic role for uric acid in hypertension and cardiovascular and renal disease?" Hypertension, vol. 41, no. 6, pp. 11831190, 2003.

[126] E. Manzato, "Uric acid: An old actor for a new role," Internal and Emergency Medicine, vol. 2, no. 1, pp. 1-2, 2007.

[127] Y. Y. Sautin and R. J. Johnson, "Uric acid: the oxidantantioxidant paradox," Nucleosides, Nucleotides and Nucleic Acids, vol. 27, no. 6-7, pp. 608-619, 2008.

[128] G. Lazarevic, S. Antic, T. Cvetkovic, P. Vlahovic, I. Tasic, and V. Stefanovic, "A physical activity programme and its effects on insulin resistance and oxidative defense in obese male patients with type 2 diabetes mellitus," Diabetes and Metabolism, vol. 32, no. 6, pp. 583-590, 2006.

[129] R. S. Rector, S. O. Warner, Y. Liu et al., "Exercise and diet induced weight loss improves measures of oxidative stress and insulin sensitivity in adults with characteristics of the metabolic syndrome," American Journal of Physiology, vol. 293, no. 2, pp. E500-E506, 2007.

[130] H. K. Vincent, C. Bourguignon, and K. R. Vincent, "Resistance training lowers exercise-induced oxidative stress and homocysteine levels in overweight and obese older adults," Obesity, vol. 14, no. 11, pp. 1921-1930, 2006.

[131] V. N. Oliveira, A. Bessa, M. L. Jorge et al., "The effect of different training programs on antioxidant status, oxidative stress, and metabolic control in type 2 diabetes," Applied Physiology, Nutrition, and Metabolism, vol. 37, no. 2, pp. 334344, 2012.

[132] C. Kasapis and P. D. Thompson, "The effects of physical activity on serum C-reactive protein and inflammatory markers: a systematic review," Journal of the American College of Cardiology, vol. 45, no. 10, pp. 1563-1569, 2005.

[133] K. E. Fallon, S. K. Fallon, and T. Boston, "The acute phase response and exercise: court and field sports," British Journal of Sports Medicine, vol. 35, no. 3, pp. 170-173, 2001.

[134] U. N. Das, "Anti-inflammatory nature of exercise," Nutrition, vol. 20, no. 3, pp. 323-326, 2004.

[135] A. M. W. Petersen and B. K. Pedersen, "The anti-inflammatory effect of exercise," Journal of Applied Physiology, vol. 98, no. 4, pp. 1154-1162, 2005.

[136] R. Starkie, S. R. Ostrowski, S. Jauffred, M. Febbraio, and B. K. Pedersen, "Exercise and IL-6 infusion inhibit endotoxininduced TNF-alpha production in humans," The FASEB Journal, vol. 17, no. 8, pp. 884-886, 2003.

[137] B. K. Pedersen and M. A. Febbraio, "Muscle as an endocrine organ: focus on muscle-derived interleukin-6," Physiological Reviews, vol. 88, no. 4, pp. 1379-1406, 2008.

[138] E. Z. Fisman and A. Tenenbaum, "The ubiquitous interleukin-6: a time for reappraisal," Cardiovascular Diabetology, vol. 9, article 62, 2010.

[139] B. K. Pedersen, "IL-6 signalling in exercise and disease," Biochemical Society Transactions, vol. 35, no. 5, pp. 12951297, 2007.

[140] M. A. Febbraio and B. K. Pedersen, "Muscle-derived interleukin-6: mechanisms for activation and possible biological roles," The FASEB Journal, vol. 16, no. 11, pp. 1335-1347, 2002.

[141] P. Matthys, T. Mitera, H. Heremans, J. Van Damme, and A. Billiau, "Anti-gamma interferon and anti-interleukin-6 antibodies affect staphylococcal enterotoxin B-induced weight loss, hypoglycemia, and cytokine release in D-galactosaminesensitized and unsensitized mice," Infection and Immunity, vol. 63, no. 4, pp. 1158-1164, 1995.

[142] C. Keller, P. Keller, M. Giralt, J. Hidalgo, and B. K. Pedersen, "Exercise normalises overexpression of TNF- $\alpha$ in knockout mice," Biochemical and Biophysical Research Communications, vol. 321, no. 1, pp. 179-182, 2004.

[143] K. R. Wilund, "Is the anti-inflammatory effect of regular exercise responsible for reduced cardiovascular disease?" Clinical Science, vol. 112, no. 11-12, pp. 543-555, 2007.

[144] K. A. Simpson and M. A. F. Singh, "Effects of exercise on adiponectin: a systematic review," Obesity, vol. 16, no. 2, pp. 241-256, 2008.

[145] T. Yatagai, Y. Nishida, S. Nagasaka et al., "Relationship between exercise training-induced increase in insulin sensitivity and adiponectinemia in healthy men," Endocrine Journal, vol. 50, no. 2, pp. 233-238, 2003.

[146] A. D. Kriketos, S. K. Gan, A. M. Poynten, S. M. Furler, D. J. Chisholm, and L. V. Campbell, "Exercise increases adiponectin levels and insulin sensitivity in humans," Diabetes Care, vol. 27, no. 2, pp. 629-630, 2004.

[147] M. Blüher, J. W. Bullen, J. H. Lee et al., "Circulating adiponectin and expression of adiponectin receptors in human skeletal muscle: associations with metabolic parameters and insulin resistance and regulation by physical training," Journal of Clinical Endocrinology and Metabolism, vol. 91, no. 6, pp. 2310-2316, 2006.

[148] L. Martin-Cordero, J. J. Garcia, E. Giraldo, M. De la Fuente, R. Manso, and E. Ortega, "Influence of exercise on the circulating levels and macrophage production of IL-1 $\beta$ and IFN $\gamma$ affected by metabolic syndrome: an obese Zucker rat experimental animal model," European Journal of Applied Physiology, vol. 107, no. 5, pp. 535-543, 2009.

[149] L. Martín-Cordero, J. J. García, M. D. Hinchado, E. Bote, R. Manso, and E. Ortega, "Habitual physical exercise improves macrophage IL- 6 and TNF- $\alpha$ deregulated release in the obese zucker rat model of the metabolic syndrome," NeuroImmunoModulation, vol. 18, no. 2, pp. 123-130, 2010.

[150] K. R. Rabin, Y. Kamari, I. Avni, E. Grossman, and Y. Sharabi, "Adiponectin: linking the metabolic syndrome to its cardiovascular consequences," Expert Review of Cardiovascular Therapy, vol. 3, no. 3, pp. 465-471, 2005.

[151] R. L. Hull, G. T. Westermark, P. Westermark, and S. E. Kahn, "Islet amyloid: a critical entity in the pathogenesis of type 2 diabetes," Journal of Clinical Endocrinology and Metabolism, vol. 89, no. 8, pp. 3629-3643, 2004.

[152] A. K. Andersson, M. Flodström, and S. Sandler, "Cytokineinduced inhibition of insulin release from mouse pancreatic $\beta$-cells deficient in inducible nitric oxide synthase," Biochemical and Biophysical Research Communications, vol. 281, no. 2, pp. 396-403, 2001.

[153] M. Y. Donath, M. Böni-Schnetzler, H. Ellingsgaard, P. A. Halban, and J. A. Ehses, "Cytokine production by islets in health and diabetes: cellular origin, regulation and function," Trends in Endocrinology and Metabolism, vol. 21, no. 5, pp. 261-267, 2010.

[154] K. Minato, Y. Shiroya, Y. Nakae, and T. Kondo, "The effect of chronic exercise on the rat pancreas," International Journal of Pancreatology, vol. 27, no. 2, pp. 151-156, 2000.

[155] K. Shima, Z. Min, Y. Noma et al., "Exercise training in Otsuka Long-Evans Tokushima Fatty rat, a model of spontaneous non-insulin-dependent diabetes mellitus: effects on the Bcell mass, insulin content and fibrosis in the pancreas," 
Diabetes Research and Clinical Practice, vol. 35, no. 1, pp. 1119, 1997.

[156] F. Dela, M. E. von Linstow, K. J. Mikine, and H. Galbo, "Physical training may enhance beta-cell function in type 2 diabetes," American Journal of Physiology, vol. 287, no. 5, pp. 1024-1031, 2004.

[157] B. K. Pedersen, "The diseasome of physical inactivity—and the role of myokines in muscle-fat cross talk," Journal of Physiology, vol. 587, no. 23, pp. 5559-5568, 2009.

[158] M. C. Gomez-Cabrera, E. Domenech, M. Romagnoli et al., "Oral administration of vitamin $\mathrm{C}$ decreases muscle mitochondrial biogenesis and hampers training-induced adaptations in endurance performance," American Journal of Clinical Nutrition, vol. 87, no. 1, pp. 142-149, 2008.

[159] M. C. Gomez-Cabrera, E. Domenech, and J. Viña, "Moderate exercise is an antioxidant: upregulation of antioxidant genes by training," Free Radical Biology and Medicine, vol. 44, no. 2, pp. 126-131, 2008.

[160] S. Sachdev and K. J. A. Davies, "Production, detection, and adaptive responses to free radicals in exercise," Free Radical Biology and Medicine, vol. 44, no. 2, pp. 215-223, 2008. 


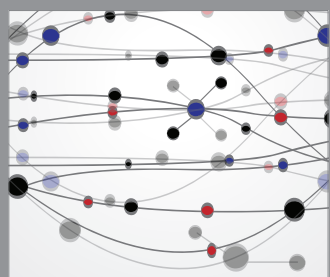

The Scientific World Journal
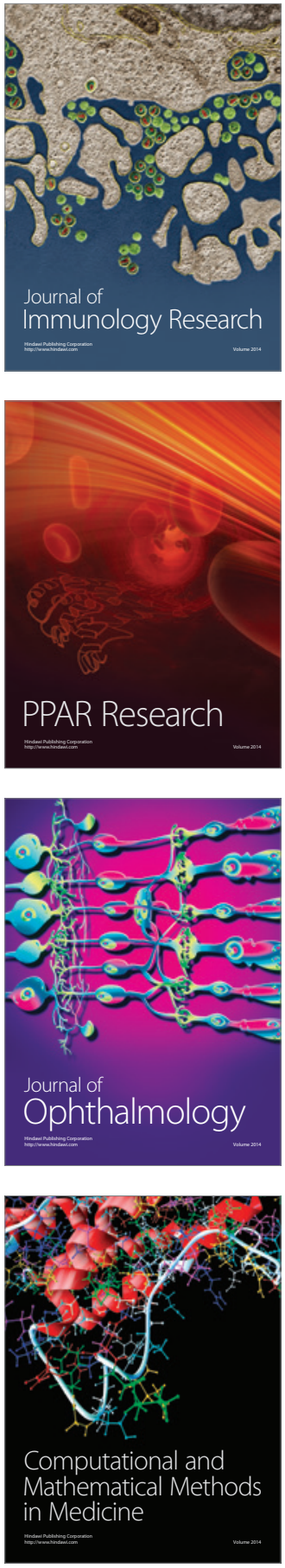

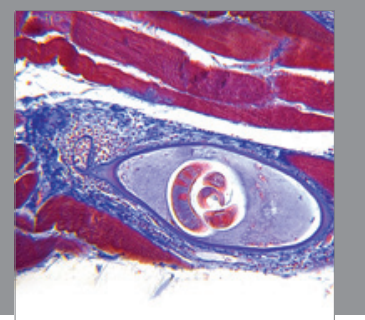

Gastroenterology

Research and Practice
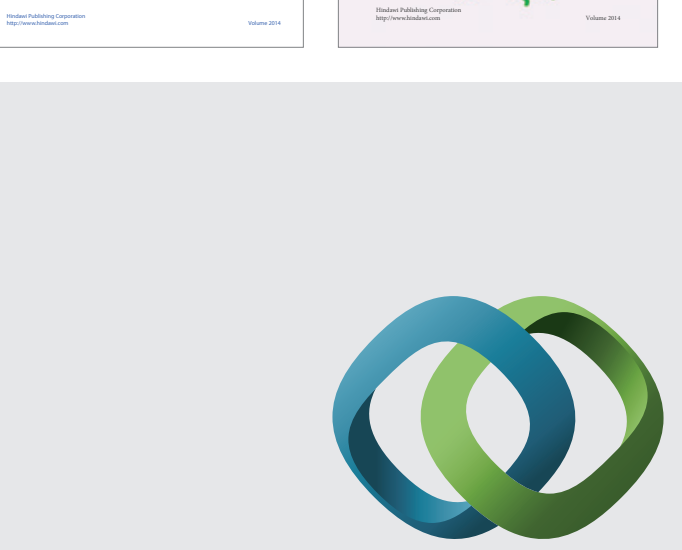

\section{Hindawi}

Submit your manuscripts at

http://www.hindawi.com
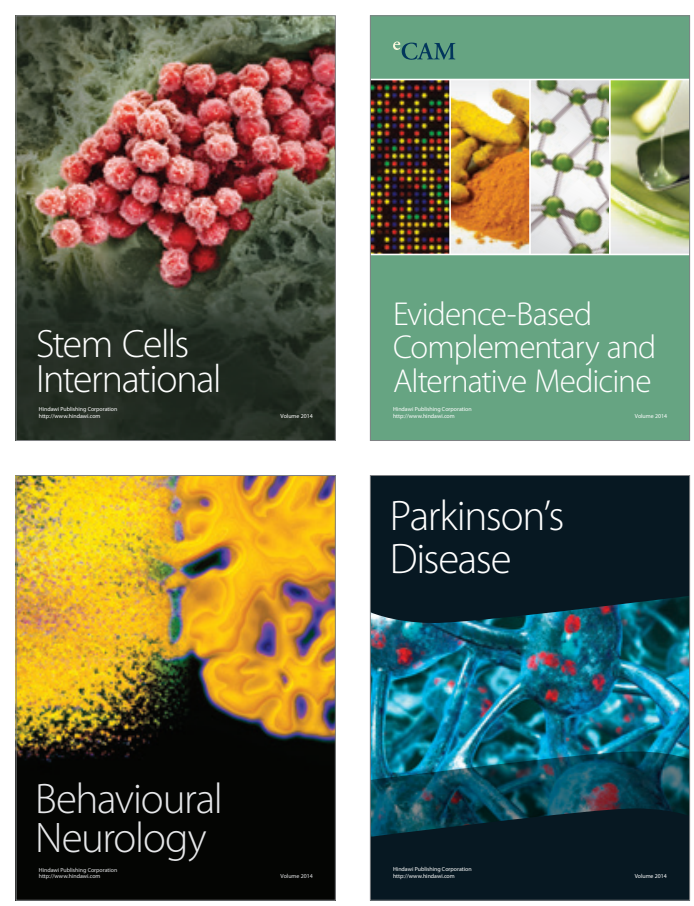

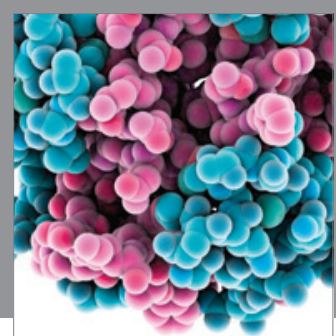

Journal of
Diabetes Research

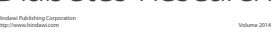

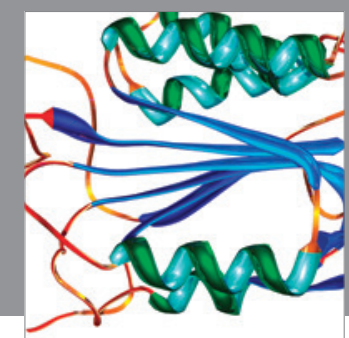

Disease Markers
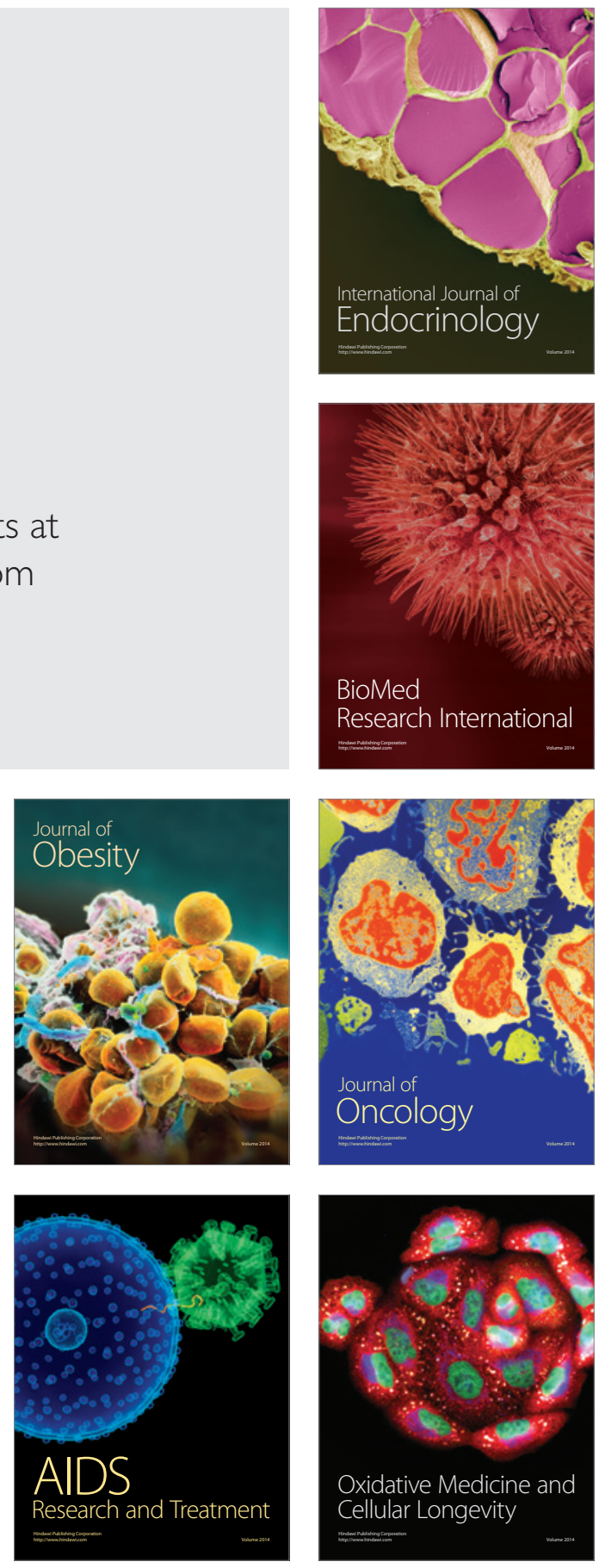